Article

\title{
The Effect of Some Fluoroquinolone Family Members on Biospeciation of Copper(II), Nickel(II) and Zinc(II) Ions in Human Plasma
}

\author{
Predrag Djurdjevic ${ }^{1{ }^{*},}$, Ivan Jakovljevic ${ }^{1}$, Ljubinka Joksovic ${ }^{1}$, Nevena Ivanovic ${ }^{1}$ and \\ Milena Jelikic-Stankov ${ }^{2}$
}

1 Faculty of Science, Chemistry Department, University of Kragujevac, P.O.BOX 60, 34000 Kragujevac, Serbia; E-Mails: ivan_jakovljevic@kg.ac.rs (I.J.); ljubinka@kg.ac.rs (L.J.); n.ivanovic@kg.ac.rs (N.I.)

2 Faculty of Pharmacy, Analytical Chemistry Department, University of Belgrade, 11221 Belgrade, Serbia; E-Mail: mjstankov@pharmacy.bg.ac.rs

* Author to whom correspondence should be addressed; E-Mail: preki@kg.ac.rs; Tel.: +381-34-300-261.

Received: 24 June 2014; in revised form: 25 July 2014 / Accepted: 30 July 2014 /

Published: 13 August 2014

\begin{abstract}
The speciation of $\mathrm{Cu}^{2+}, \mathrm{Ni}^{2+}$ and $\mathrm{Zn}^{2+}$ ions in the presence of the fluoroquinolones (FQs) moxifloxacin, ofloxacin, levofloxacin and ciprofloxacin, in human blood plasma was studied under physiological conditions by computer simulation. The speciation was calculated using an updated model of human blood plasma including over 6,000 species with the aid of the program Hyss2009. The identity and stability of metal-FQ complexes were determined by potentiometric $(310 \mathrm{~K}, 0.15 \mathrm{~mol} / \mathrm{L} \mathrm{NaCl})$, spectrophotometric, spectrofluorimetric, ESI-MS and ${ }^{1} \mathrm{H}-\mathrm{NMR}$ measurements. In the case of $\mathrm{Cu}^{2+}$ ion the concentration of main low molecular weight (LMW) plasma complex $(\mathrm{Cu}(\mathrm{Cis}) \mathrm{His})$ is very slightly influenced by all examined FQs. FQs show much higher influence on main plasma $\mathrm{Ni}^{2+}$ and $\mathrm{Zn}^{2+}$ complexes: (Ni(His) $)_{2}$ and $\mathrm{Zn}(\mathrm{Cys}) \mathrm{Cit}$, respectively. Levofloxacin exhibits the highest influence on the fraction of the main nickel complex, $\mathrm{Ni}(\mathrm{His})_{2}$, even at a concentration level of $3 \times 10^{-5} \mathrm{~mol} / \mathrm{L}$. The same effect is seen on the main zinc complex, $\mathrm{Zn}(\mathrm{Cys}) \mathrm{Cit}$. Calculated plasma mobilizing indexes indicate that ciprofloxacin possesses the highest mobilizing power from plasma proteins, toward copper ion, while levofloxacin is the most influential on nickel and zinc ions. The results obtained indicate that the drugs studied are safe in relation to mobilization of essential metal ions under physiological conditions. The observed effects were explained in terms of competitive equilibrium reactions between the FQs and the main LMW complexes of the metal ions.
\end{abstract}


Keywords: copper; nickel; zinc; fluoroquinolones; complexes; biospeciation; blood plasma; computer simulation

\section{Introduction}

Elemental speciation in biological fluids, particularly human plasma, implies investigation of the association between the trace element and available bioligands: proteins and compounds with relatively low molecular weight (LMW). These investigations constitute a basis of metabolic and kinetic studies and are also used to explain the mobility, storage retention and toxicity of metal ions [1]. Chemical speciation of trace metals in human blood plasma has been discussed in several review articles [2,3], but the literature on speciation of metal ions in biological fluids, as a whole, is rather limited. There were two general approaches to the problem of metal speciation: the experimental one and by computer simulation. The experimental approach is focused on developing the instrumental methods for the determination of total and free metal ion concentrations, fraction bond to proteins and fraction of total metal distributed between various LMW ligands. However, since the most of the developed experimental methods considerably disturb the labile equilibria between metal ions and LMW ligands, they are not capable of accurately determining the very low levels of complex species concentrations existing in biological matrices [4]. Thus, biospeciation of trace metal ions is commonly studied by computer simulation. Two approaches are common: (a) minimization of total Gibbs-free energy of the multi-component system, subjected to the constraints of the elemental mass balance. This approach is used in geochemical and chemical engineering simulations; and (b) equilibrium calculations based on calculation of concentrations by solving the system of mass balance equations. This approach is often used in solution chemistry and requires knowledge of the identity and stability of all metal complexes presented in biological compartment (e.g. human plasma). The aim of the computer simulation of trace element distribution in human blood plasma is to calculate the relative percentages of all presented LMW complexes of metal ions and to assess their distribution under various conditions. This task is of great significance owing to the important role of these complexes in many physiological processes taking place in blood plasma. According to May et al. [5], trace metals in blood plasma may be classified into four fractions: (a) non-exchangeable i.e. tightly bound to the metaloproteins; (b) exchangeable, loosely bound by proteins; (c) complexed by LMW ligands; (d) free (hydrated) metal ions. To calculate the concentration of LMW complexes the binding constants of metal-protein complexes are required, but the relative percentage distribution of trace metal ions amongst the LMW ligands is not controlled by protein binding and so the metal protein equilibria can be bypassed in the plasma model [6].

Metal ions enter human body mainly from food and drink but their sources may also include industrial particulate matter, medicines, etc. In blood plasma, they are transported through specific intestinal and/or gastric channels in the form of free (aquated ions) or complexed species with various types of endogenous or exogenous ligands [7].

Copper is an essential element which plays a critical role in human metabolism. Although, copper exists in both of its common oxidation states $\mathrm{Cu}^{2+}$ and $\mathrm{Cu}^{+}$, so far reported models of copper speciation 
in human blood plasma have mainly focused on $\mathrm{Cu}^{2+}$ speciation. In blood plasma, $65 \%$ of the copper is irreversibly bond to ceruloplasmin (non-exchangeable), $\sim 12 \%$ to transcuprein, $\sim 12 \%$ is loosely bond to albumin, and a small amount is distributed amongst LMW complexes [8]. It is well established that mixed ligand ternary complexes with histidine are predominant. It was assumed by Ho at al. [9] and May et al. [5] that the total $\mathrm{Cu}^{2+}$ concentration in plasma is $1.6 \times 10^{-11} \mathrm{~mol} / \mathrm{L}$ and free concentration is $5.1 \times 10^{-16} \mathrm{~mol} / \mathrm{L}$.

Nickel is an essential constituent of methyl-CoM reductase, $\mathrm{CO}$ dehydrogenase and hydrogenase in some strains of bacteria. Its physiological role in human organism is not yet fully elucidated. It is capable of activating or inhibiting a number of enzymes, altering cell membrane properties and influencing various redox processes. The main carrier proteins of nickel in serum are albumin and nickeloplasmin, but it can also be bound to $\alpha$-2-macroglobulin. Plasma concentration is $10^{-7}-10^{-9} \mathrm{~mol} / \mathrm{L}$ and free concentration in plasma is $\sim 1.0 \times 10^{-11} \mathrm{~mol} / \mathrm{L}$. Of all LMW ligands, nickel is most strongly bound to histidine [10].

Zinc is an essential trace element whose total concentration in blood plasma is $1.6 \times 10^{-5} \mathrm{~mol} / \mathrm{L}$ and free concentration $10^{-9} \mathrm{~mol} / \mathrm{L}$. $\mathrm{Zn}^{2+}$ is rigidly bound to $\alpha$-2-macroglobulin and as exchangeable fraction to albumin and serum transferrin. Its main LMW complex is with cysteine and ternary complexes with cysteine and histidine [11].

Fluoroquinolones (FQ) are synthetic antibacterial agents which could act as the competitive LMW ligands for trace metal ions in blood plasma [12-14]. They may remove metal ions from their protein complexes and compete with other naturally occurred ligands in blood plasma for metal binding. Its relative ability to compete for metal ions in blood plasma can be assessed in terms of the plasma mobilizing index (PMI) proposed by May and Williams [15]. The PMI may be used to determine fluoroquinolone effectiveness at mobilizing $\mathrm{Cu}^{2+}, \mathrm{Ni}^{2+}$ or $\mathrm{Zn}^{2+}$ in blood plasma. PMI is defined as:

$$
\frac{T_{L M W}^{(E L)}}{T_{L M W}}=P M I
$$

where $T_{L M W}^{(E L)}$ is the total concentration of the LMW metal ion fraction in the presence of exogenously administered chelating agents and $T_{L M W}$ is the total concentration of the LMW metal ion fraction in normal plasma. The PMI may serve to compare mobilizing power of various ligands toward particular metal ion. It permits assessment of the capacity of exogenous ligand to increase the amount of the LMW metal ion fraction at the expense of the protein bound metal. The percentage distribution of metal ions in the LMW fraction is computed assuming that the metal-protein complex is buffer free metal ion concentrations in plasma.

Based on our previously described blood plasma model [16], the aim of the present work was to establish the ability of some members of fluoroquinolone antibacterial agents to mobilize trace metal ions from blood plasma. The obtained data are essential for elucidating the mechanism of action of fluoroquinolones and the influence of metal ions on this mechanism. In addition the obtained results may be used to assess the safety of FQs toward mobilization of metal ions and consequent change of their metabolic pathways.

In this work we studied the effect of a number of FQs (ciprofloxacin-Cipro, ofloxacin-Oflo, levofloxacin-Levo and moxifloxacin-Moxi) on the biodistribution of $\mathrm{Cu}^{2+}, \mathrm{Ni}^{2+}$ and $\mathrm{Zn}^{2+}$ ions using the equilibrium calculations method. The goal of this investigation was to evaluate the capacity of some 
fluoroquinolone antibacterial agents to influence the LMW metal ions fraction in plasma and rationalize their ability to compete for metal ions with endogenous plasma ligands.

\section{Results and Discussion}

\subsection{Potentiometric and Spectrophotometric Measurements}

The protonation equilibria of FQ anions were studied before complexation measurements using both potentiometry and spectrophotometry, under the same conditions as used in the complexation study. The complex formation constants between metal cations $\left(\mathrm{Cu}^{2+}, \mathrm{Ni}^{2+}\right.$ and $\left.\mathrm{Zn}^{2+}\right)$ and quinolones were investigated by emf titrations in $0.15 \mathrm{M}(\mathrm{NaCl})$ solution at $\mathrm{T}=310 \mathrm{~K}$. Representative titration curves obtained for solutions containing moxifloxacin and metal cations are illustrated in Figure 1.

Figure 1. Titration curves for moxifloxacin and moxifloxacin + metal cations with $\mathrm{NaOH}$ at $310 \mathrm{~K}$ and $\mathrm{I}=0.15 \mathrm{M}(\mathrm{NaCl})$. Concentration of metal cations: $1.0 \mathrm{mmol} / \mathrm{L}$, concentration of moxifloxacin: $2.0 \mathrm{mmol} / \mathrm{L}$.

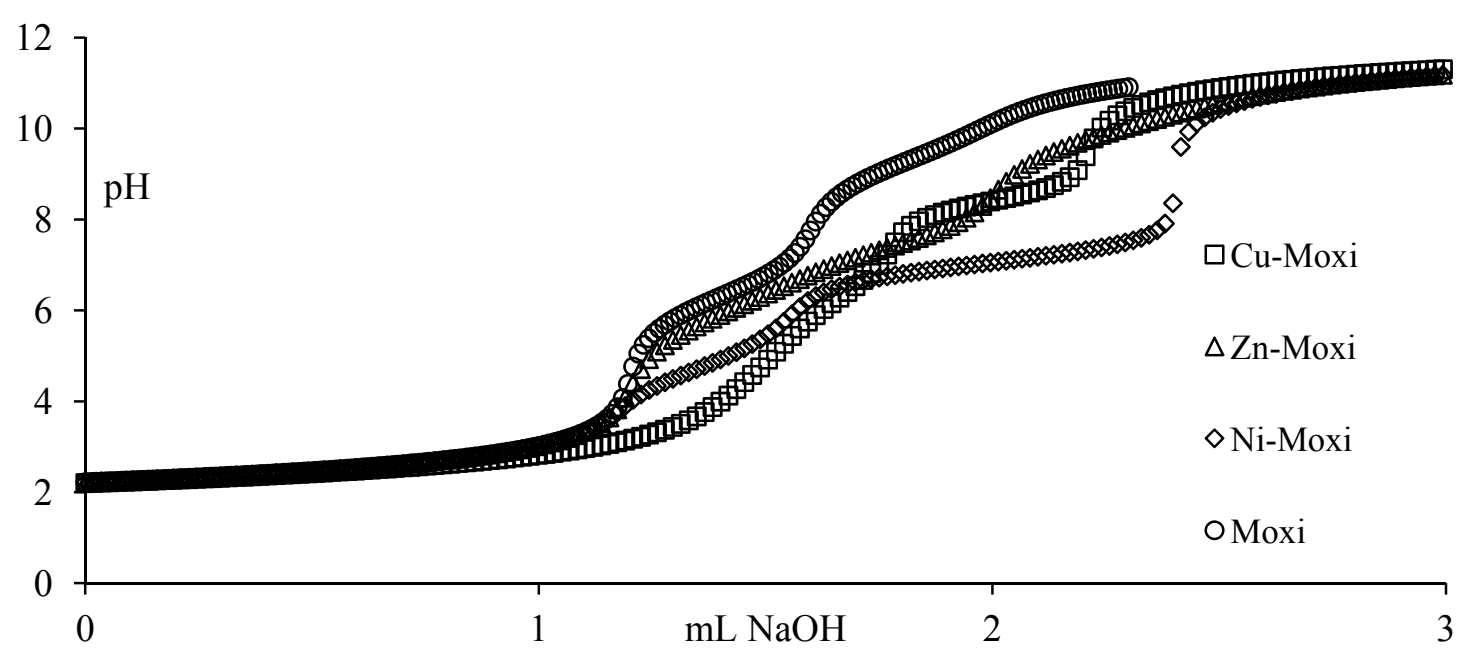

The $\mathrm{pH}$ titration of moxifloxacin in diprotonated form shows that the two protons dissociate in individual steps at $a=1-2$ and $a=2-3$ corresponding to the dissociation of the carboxyl and amine groups, respectively. The titration parameter $a$ represents the number of moles of strong base added per mole of quinolone and was calculated through the formula:

$$
a=\frac{C_{N a O H} V_{N a O H}-V_{0} C_{H C l}}{V_{0} L}
$$

where $V_{0}$ and $L$ are the initial volume and concentration of fluoroquinolone in the titrated solution. Below $a=1$ strong acid $(\mathrm{HCl})$ is titrated. It can be seen that moxifloxacin is present in solution in the whole titration range. In the presence of metal cations the titration curves are shifted due to the formation of metal complexes. These curves showed that complex formation begins from a low $\mathrm{pH}$ value and mainly occurs in the deprotonation region of the carboxyl group of moxifloxacin. The titration curves patterns of other FQs were similar to those of moxifloxacin. Precipitation was observed at $\mathrm{pH}$ values between $\mathrm{pH} 7-8$. When precipitates formed the titrations were stopped and the corresponding points were excluded from calculations. 
To complement potentiometric measurements, spectrophotometric data were also obtained for metal-quinolone systems. The UV spectra in the presence of the metal cations of all FQs studied were always compared with the corresponding UV spectra of the free FQs. Spectral measurements of metal (II) + FQ solutions show evidence of an intensive higher energy band situated between 285 and 295 and lower energy broad band between 320 and $380 \mathrm{~nm}$ for all $\mathrm{M}^{2+}+\mathrm{FQ}$ systems (Figure 2). Upon increasing the $\mathrm{pH}$ from 3 to 9 the higher energy band shows only small changes in position and maximum intensity (hypsochromic shift). The lower energy band exhibits however, significant changes in a shape, position and intensity (bathochromic shift). Wavelengths of maximum absorptions of free quinolones and metal-quinolones solutions are given in Table 1. In comparison with the free FQ spectra, the higher energy band may be attributed to fluoroquinolone nucleus while the lower energy band may be attributed to metal carbonyl and metal carboxyl bonds overlapping absorption. The presence of isosbestic points can be attributed not only to equilibria between protonation forms of the ligand but also proved that the different complexes were formed in solution. In the presence of metal ion, in comparison with the spectrum of fluoroquinolone alone, all bands are shifted toward higher wavelengths (Table 1).

Figure 2. UV-Vis spectra of $\mathrm{Cu}^{2+}$-moxifloxacin solutions against free moxifloxacin as a blank. $\left(\mathrm{C}_{\mathrm{Cu}}=2.5 \times 10^{-5} \mathrm{~mol} / \mathrm{L}, \mathrm{C}_{\text {Moxi }}=5 \times 10^{-5} \mathrm{~mol} / \mathrm{L}, \mathrm{I}=0.15 \mathrm{~mol} / \mathrm{L} \mathrm{NaCl}, \mathrm{T}=310 \mathrm{~K}\right)$.

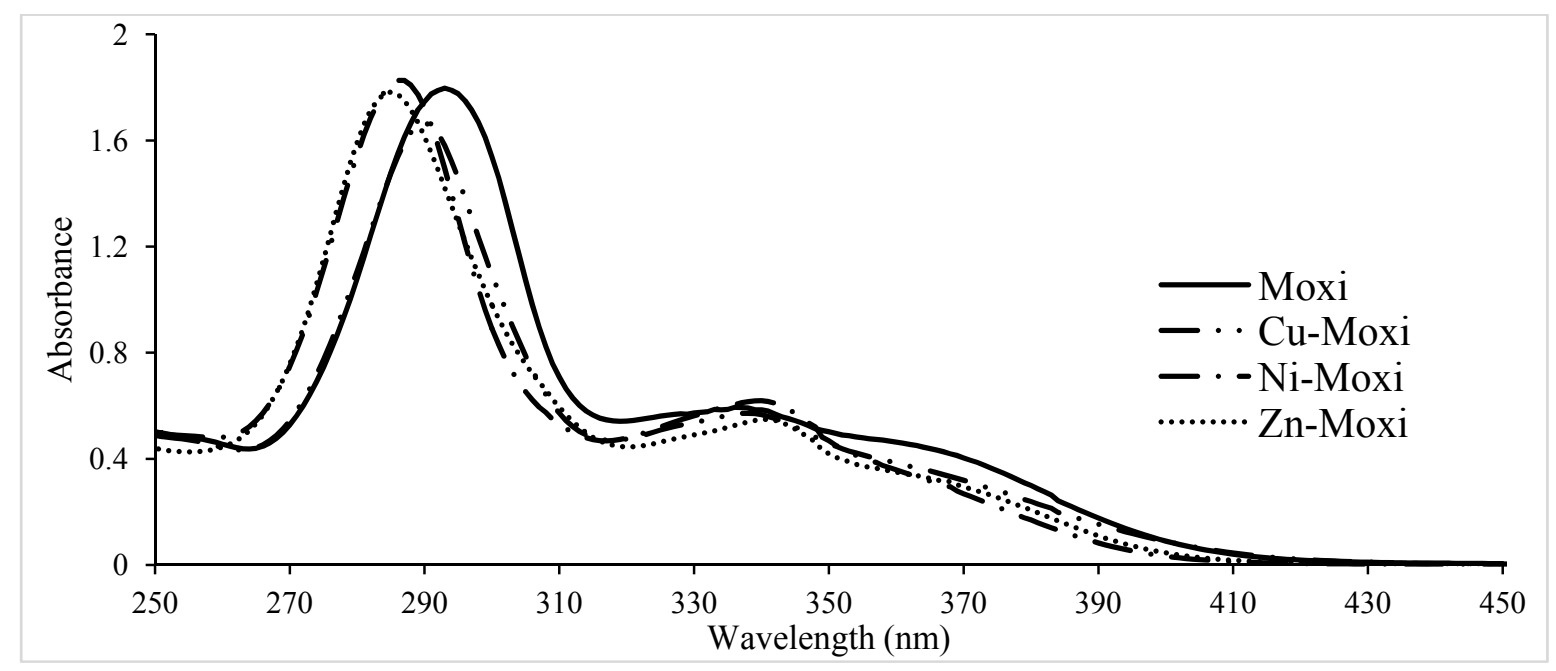

Table 1. Maximum UV absorption of fluoroquinolones and their complexes at $\mathrm{pH}=7.4$.

\begin{tabular}{ccc} 
& $\boldsymbol{\lambda}_{\mathbf{1}}{ }^{\mathbf{m a x}} \mathbf{( n m )}$ & $\boldsymbol{\lambda}_{\mathbf{2}}{ }^{\mathbf{m a x}} \mathbf{( n m )}$ \\
Moxifloxacin & 289 & 340 \\
Cu-Moxi & 292 & 336 \\
Ni-Moxi & 288 & 340 \\
Levofloxacin & 288 & 332 \\
Cu-Levo & 292 & 326 \\
Ni-Levo & 288 & 330 \\
\hline
\end{tabular}

Stability constants were calculated with Hyperquad2006 suite of programs [17]. To find the model that gives the best fit to the experimental data, various complexes and combinations thereof were included in calculations. During the calculations, the analytical parameters (total metal, ligand and 
proton concentration) were held constant. The pure hydrolytic complexes and protonated fluoroquinolone species were not refined during the calculations. First, the potentiometric and spectrophotometric data were separately calculated until the best set of complexes was found. For spectral data the program pHab was utilized. Then both kinds of data were treated together in Hypequad2006. The calculated protonation constants are presented in Table 2 . The calculated overall stability constants of complexes are given in Table 3.

They are in good agreement with so far published data. From Table 3 it can be seen that in all systems $\mathrm{M}(\mathrm{FQH})^{2+}$ and $\mathrm{M}(\mathrm{FQ})_{2}{ }^{0}$ complexes were found. Overall stability constants of fluoroquinolones with these divalent metal ions follow the Irving-Williams series as expected $(\mathrm{Cu} \geq \mathrm{Ni}>\mathrm{Zn})$.

Table 2. Calculated protonation constants $(\log \beta \pm \mathrm{SD})$ for fluoroquinolones compared with literature values.

\begin{tabular}{|c|c|c|c|c|c|c|}
\hline FQ & Methods & $\log \beta_{1}{ }^{H}$ & $\log \beta_{2}{ }^{H}$ & Ionic Medium & $\mathbf{T}^{\circ} \mathbf{C}$ & Reference \\
\hline \multirow{7}{*}{ Cipro } & UV/POT & 8.81 & 14.71 & $0.15 \mathrm{M} \mathrm{NaCl}$ & 37 & this work \\
\hline & POT & 8.95 & 15.10 & $0.1 \mathrm{M} \mathrm{NaCl}$ & 25 & {$[18]$} \\
\hline & UV & 8.89 & 14.79 & $0.05 \mathrm{M} \mathrm{NaAc}$ & 25 & [19] \\
\hline & UV & 8.73 & 14.91 & $0.2 \mathrm{M} \mathrm{NaCl}$ & 25 & {$[20]$} \\
\hline & UV & 8.84 & 15.17 & 1 & / & [21] \\
\hline & POT & 7.41 & 13.55 & $0.1 \mathrm{M} \mathrm{NaNO} 3$ & l & {$[22]$} \\
\hline & POT & 8.62 & 14.71 & 0 & 25 & [23] \\
\hline \multirow{7}{*}{ Oflo } & UV/POT & 8.27 & 14.31 & $0.15 \mathrm{M} \mathrm{NaCl}$ & 37 & this work \\
\hline & POT & 8.60 & 14.70 & $0.1 \mathrm{M} \mathrm{NaCl}$ & 25 & [18] \\
\hline & UV & 7.18 & I & / & / & {$[24]$} \\
\hline & POT & 8.28 & 14.38 & / & / & [24] \\
\hline & UV & 8.28 & 14.25 & $0.05 \mathrm{NaAc}$ & 25 & [19] \\
\hline & POT & 8.11 & 14.16 & 0 & 25 & {$[23]$} \\
\hline & POT & 7.88 & 1 & $0.1 \mathrm{M} \mathrm{NaNO}_{3}$ & 1 & {$[23]$} \\
\hline \multirow{8}{*}{ Moxi } & UV/POT & 9.27 & 15.58 & $0.15 \mathrm{M} \mathrm{NaCl}$ & 37 & this work \\
\hline & POT & 9.53 & 15.76 & $0.1 \mathrm{M} \mathrm{NaCl}$ & 1 & {$[18]$} \\
\hline & POT & 9.29 & 15.54 & $0.15 \mathrm{M} \mathrm{NaCl}$ & / & {$[25]$} \\
\hline & UV & 8.72 & 14.88 & / & 25 & {$[26]$} \\
\hline & POT & 9.53 & 15.76 & $0.1 \mathrm{M} \mathrm{NaCl}$ & 25 & [27] \\
\hline & UV/POT & 9.32 & 15.67 & $0.1 \mathrm{M} \mathrm{LiCl}$ & $5^{2}$ & [28] \\
\hline & UV & 9.3 & 15.57 & $0.1 \mathrm{M} \mathrm{LiCl}$ & 25 & [29] \\
\hline & POT & 9.34 & 15.67 & $0.1 \mathrm{M} \mathrm{LiCl}$ & 25 & [29] \\
\hline \multirow{3}{*}{ Levo } & UV/POT & 7.90 & 13.68 & $0.15 \mathrm{M} \mathrm{NaCl}$ & 37 & this work \\
\hline & POT & 8.15 & 14.17 & $0.1 \mathrm{M} \mathrm{NaCl}$ & 25 & [18] \\
\hline & POT & 8.15 & 14.17 & $0.1 \mathrm{MNaCl}$ & 25 & [30] \\
\hline
\end{tabular}


Table 3. Calculated overall stability constants $\left(\log \beta_{\mathrm{pqr}} \pm \mathrm{SD}\right)$ for complexes present in $\mathrm{M}^{2+}$-FQ $\left(\mathrm{M}_{\mathrm{p}} \mathrm{FQ}_{\mathrm{q}} \mathrm{H}_{\mathrm{r}}\right)$ systems at physiological conditions $\left(\mathrm{T}=37{ }^{\circ} \mathrm{C}\right.$ and $\left.\mathrm{I}=0.15 \mathrm{M} \mathrm{NaCl}\right)$.

\begin{tabular}{|c|c|c|c|c|}
\hline \multirow[b]{2}{*}{$\mathbf{p q r}$} & \multicolumn{4}{|c|}{ Cu-FQ } \\
\hline & Ciprofloxacin & Levofloxacin & Ofloxacin & Moxifloxacin \\
\hline 111 & $14.89 \pm 0.22$ & $13.74 \pm 0.04$ & $14.21 \pm 0.03$ & $15.77 \pm 0.03$ \\
\hline $12-1$ & $6.13 \pm 0.21$ & $1.66 \pm 0.06$ & $1.88 \pm 0.04$ & $6.71 \pm 0.04$ \\
\hline 120 & $16.06 \pm 0.11$ & $11.08 \pm 0.03$ & $11.31 \pm 0.02$ & $12.92 \pm 0.02$ \\
\hline 121 & $22.6 \pm 0.22$ & $19.18 \pm 0.04$ & $19.42 \pm 0.03$ & $23.51 \pm 0.03$ \\
\hline 122 & $29.06 \pm 0.15$ & $26.25 \pm 0.03$ & $26.56 \pm 0.03$ & $29.89 \pm 0.03$ \\
\hline statistics & $\begin{aligned} \mathrm{s} & =1.87 \\
\chi^{2} & =12.46\end{aligned}$ & $\begin{array}{c}s=0.54 \\
\chi^{2}=5.46\end{array}$ & $\begin{array}{c}s=0.78 \\
\chi^{2}=3.54\end{array}$ & $\begin{array}{c}\mathrm{s}=1.23 \\
\chi^{2}=5.49\end{array}$ \\
\hline \multicolumn{5}{|c|}{ Ni-FQ } \\
\hline $\mathbf{p q r}$ & Ciprofloxacin & Levofloxacin & Ofloxacin & $\begin{array}{l}\text { Moxiflox } \\
\text { acin } \\
\end{array}$ \\
\hline 111 & $14.92 \pm 0.22$ & $13.76 \pm 0.04$ & $16.61 \pm 0.03$ & $12.72 \pm 0.03$ \\
\hline $12-1$ & $6.32 \pm 0.21$ & $8.48 \pm 0.06$ & $8.84 \pm 0.04$ & $4.62 \pm 0.04$ \\
\hline 120 & $16.95 \pm 0.11$ & $16.3 \pm 0.03$ & $16.62 \pm 0.02$ & $13.87 \pm 0.02$ \\
\hline 121 & $22.34 \pm 0.22$ & $23.89 \pm 0.04$ & $24.23 \pm 0.03$ & $19.52 \pm 0.03$ \\
\hline 122 & $28.98 \pm 0.15$ & $29.18 \pm 0.03$ & $29.58 \pm 0.03$ & $27.54 \pm 0.03$ \\
\hline & $\mathrm{s}=1.47$ & $\mathrm{~s}=0.93$ & $\mathrm{~s}=1.28$ & $\mathrm{~s}=1.03$ \\
\hline statistics & $\chi^{2}=11.21$ & $\chi^{2}=4.43$ & $\chi^{2}=2.57$ & $\chi^{2}=7.52$ \\
\hline \multicolumn{5}{|c|}{ Zn-FQ } \\
\hline p q r & Ciprofloxacin & Levofloxacin & Ofloxacin & Moxifloxacin \\
\hline 111 & $12.74 \pm 0.22$ & $14.2 \pm 0.04$ & $12.9 \pm 0.03$ & $12.47 \pm 0.03$ \\
\hline 120 & $10.49 \pm 0.11$ & $9.68 \pm 0.03$ & $9.08 \pm 0.02$ & $10.56 \pm 0.02$ \\
\hline 121 & $17.82 \pm 0.22$ & $18.04 \pm 0.04$ & $17.21 \pm 0.03$ & $17.95 \pm 0.03$ \\
\hline 122 & $24.84 \pm 0.15$ & $24.26 \pm 0.03$ & $23.87 \pm 0.03$ & $24.91 \pm 0.03$ \\
\hline statistics & $\mathrm{s}=0.97$ & $\mathrm{~s}=1.55$ & $\mathrm{~s}=1.18$ & $\mathrm{~s}=1.83$ \\
\hline statistics & $\chi^{2}=12.46$ & $\chi^{2}=6.41$ & $\chi^{2}=6.34$ & $\chi^{2}=3.92$ \\
\hline
\end{tabular}

\subsection{Reliability of the Data}

In Hyperquad2006 program the quality of the fit was evaluated using the set of statistical parameters, $U, \chi^{2}$, s and $\sigma$ [17]. The calculated set of statistics generally indicate good overall fit of the experimental data. In addition the residuals in potentials were analyzed for normal probability distribution autocorrelations and systematic trends. Inspections of the residuals in potentials for the metal-FQ model that fits best experimental data shows a linear normal probability plot and a small autocorrelation length. Examination of the residuals scatter reveals that no significant systematic trends exist, so the accepted set of complexes and their stability constants gives a plausible explanation of the experimental data. Similar results were obtained with analysis of absorbance residuals.

Existing literature data on stability constants of the studied metals with some fluoroquinolones in different media and temperature ranges are given in Table 4. Comparing our and literature models reasonably good agreement is evidenced. Complexes (111), (122), (121), (120) and (12-1) were found in all studied systems except in Zn-FQ systems where (12-1) was not found. The complex $(1,1,0)$ has not been found in our calculations and the $(1,3,2)$ complex of nickel with ciprofloxacin was not found 
either. The stability constants of 1:1 and 1:2 complexes (metal to ligand) are moderately high. Owing to the low total concentrations of metals and ligands no polynuclear complexes were found. However, protonated and hydrolytic complexes are common for all systems. The proton probably resides on secondary or tertiary nitrogen in C-7 substituent, while hydrolytic species originate from the protolysis of coordinated water. The complex $\left[\mathrm{M}(\mathrm{FQ})_{2} \mathrm{H}_{2}\right]$ possesses $\log \beta$ in the range ca. 26-29 for $\mathrm{Cu}$ and $\mathrm{Ni}$ ions while with $\mathrm{Zn}$ ion $\log \beta$ is considerably smaller.

Table 4. Literature overview of stability constants of the complexes $M_{p}(F Q)_{q} H_{r}$ calculated from potentiometric measurements data of $\mathrm{M}(\mathrm{II})-\mathrm{FQ}$ systems ( $\mathrm{I}=$ ionic strength of the medium, $\mathrm{mol} / \mathrm{L}$ ).

\begin{tabular}{|c|c|c|c|c|c|c|}
\hline Metal Ion & FQ & $\mathbf{p q r}$ & $\log \beta_{p q r}$ & $\mathbf{I}$ & $\mathbf{T}\left({ }^{\circ} \mathrm{C}\right)$ & Reference \\
\hline \multirow{33}{*}{$\mathrm{Cu}$} & \multirow{8}{*}{ Oflo } & $\begin{array}{lll}1 & 1 & 1 \\
1 & 2 & 2\end{array}$ & $\begin{array}{c}12.34 \\
23.4\end{array}$ & $0.1 \mathrm{NaCl}$ & 25 & * Gameiro et al. [31] \\
\hline & & 111 & 14.21 & \multirow{7}{*}{$0.1 \mathrm{NaCl}$} & \multirow{5}{*}{22} & \multirow{5}{*}{ Urbaniak et al. [32] } \\
\hline & & 122 & 26.56 & & & \\
\hline & & 121 & 19.42 & & & \\
\hline & & 120 & 11.31 & & & \\
\hline & & $12-1$ & 1.88 & & & \\
\hline & & 111 & 14.84 & & \multirow{2}{*}{25} & \multirow{2}{*}{ * Feio et al. [18] } \\
\hline & & 122 & 28.40 & & & \\
\hline & \multirow{16}{*}{ Cipro } & 110 & 6.2 & \multirow{5}{*}{$0.15 \mathrm{NaCl}$} & 25 & \multirow{5}{*}{ Wallis et al. [33] } \\
\hline & & 110 & 6.1 & & 37 & \\
\hline & & 120 & 11.1 & & 25,37 & \\
\hline & & $12-1$ & 4.0 & & 25 & \\
\hline & & $12-1$ & 4.5 & & 37 & \\
\hline & & 111 & 14.73 & \multirow{3}{*}{$0.2 \mathrm{KCl}$} & \multirow{3}{*}{25} & \multirow{3}{*}{ Turel et al. [34] } \\
\hline & & 122 & 28.53 & & & \\
\hline & & 121 & 21.93 & & & \\
\hline & & 111 & 14.43 & & & \multirow{3}{*}{ * Feio et al. $[18]$} \\
\hline & & 110 & 6.46 & $0.1 \mathrm{NaCl}$ & 25 & \\
\hline & & 120 & 11.77 & & & \\
\hline & & 111 & 14.89 & \multirow{14}{*}{$0.1 \mathrm{NaCl}$} & \multirow{10}{*}{22} & \multirow{10}{*}{ Urbaniak et al. [32] } \\
\hline & & $12-1$ & 6.13 & & & \\
\hline & & 120 & 16.06 & & & \\
\hline & & 121 & 22.60 & & & \\
\hline & & 122 & 29.06 & & & \\
\hline & \multirow{9}{*}{ Levo } & 111 & 13.74 & & & \\
\hline & & $12-1$ & 1.66 & & & \\
\hline & & 120 & 11.08 & & & \\
\hline & & 121 & 19.18 & & & \\
\hline & & 122 & 26.25 & & & \\
\hline & & 111 & 14.37 & & \multirow{4}{*}{25} & \multirow{4}{*}{ * Feio et al. $[18]$} \\
\hline & & 110 & 7.13 & & & \\
\hline & & 122 & 27.22 & & & \\
\hline & & 120 & 11.78 & & & \\
\hline
\end{tabular}


Table 4. Cont.

\begin{tabular}{|c|c|c|c|c|c|c|}
\hline Metal Ion & FQ & $\mathbf{p q r}$ & $\log \beta_{\mathrm{pqr}}$ & I & $\mathbf{T}\left({ }^{\circ} \mathrm{C}\right)$ & Reference \\
\hline & & 111 & 15.54 & & & \\
\hline & & 110 & 8.21 & & & \\
\hline & & 122 & 31.30 & & & \\
\hline & & 120 & 14.17 & & & \\
\hline & Mox1 & 111 & 14.21 & & & \\
\hline & & 110 & 10.20 & & & \\
\hline & & 122 & 27.73 & & & \\
\hline & & 120 & 22.17 & & & \\
\hline \multirow{9}{*}{$\mathrm{Ni}$} & & 111 & 13.42 & & & \\
\hline & Oflo & 110 & 5.91 & & & \\
\hline & & 122 & 25.60 & & & \\
\hline & \multirow{13}{*}{ Cipro } & 111 & 13.41 & & & \\
\hline & & 110 & 7.43 & & & \\
\hline & & 111 & 12.93 & \multirow{4}{*}{$0.2 \mathrm{KCl}$} & \multirow{4}{*}{25} & \multirow{7}{*}{ Turel et al. [34] } \\
\hline & & 122 & 25.77 & & & \\
\hline & & 121 & 18.42 & & & \\
\hline & & 132 & 29.7 & & & \\
\hline \multirow{18}{*}{$\mathrm{Zn}$} & & 111 & 12.32 & & & \\
\hline & & 122 & 24.72 & $0.2 \mathrm{KCl}$ & 25 & \\
\hline & & 121 & 17.41 & & & \\
\hline & & 111 & 12.74 & \multirow{15}{*}{$0.1 \mathrm{NaCl}$} & \multirow{12}{*}{22} & \multirow{12}{*}{ Urbaniak et al. [32] } \\
\hline & & 120 & 10.49 & & & \\
\hline & & 121 & 17.82 & & & \\
\hline & & 122 & 24.84 & & & \\
\hline & & 111 & 14.64 & & & \\
\hline & Ofl & 120 & 10.51 & & & \\
\hline & 0 & 121 & 18.36 & & & \\
\hline & & 122 & 24.40 & & & \\
\hline & \multirow{4}{*}{ Levo } & 111 & 12.90 & & & \\
\hline & & 120 & 9.08 & & & \\
\hline & & 121 & 17.20 & & & \\
\hline & & 122 & 23.87 & & & \\
\hline & \multirow{3}{*}{ Oflo } & 111 & 12.67 & & \multirow{3}{*}{25} & \multirow{3}{*}{ * Feio et al. $[18]$} \\
\hline & & 110 & 5.23 & & & \\
\hline & & 122 & 24.48 & & & \\
\hline
\end{tabular}

* Values of stability constants were recalculated taking into account M, H and L as components instead of M and $\mathrm{HL}$ as given in the original reference.

\subsection{Solution Equilibria and Distribution Diagrams}

The distribution of various complexes in M(II)-FQ solutions are shown in Figures 3-5. In the following text the complexes are designated with an acid HMoxi as a component to make the mechanisms meaningful. HMoxi may be either neutral or a zwitterion, the latter being more probable. 
As can be seen from Figure 3, at lower $\mathrm{pH}$ values (less than 3), hydrated copper ion exists dominantly in solution. With increasing $\mathrm{pH}$ values over 3 the formation of $\mathrm{Cu}(\mathrm{HMoxi})^{2+}$ complex $(\mathrm{Cu}(\mathrm{Moxi}) \mathrm{H}$ on the distribution diagram) starts, probably according to the reaction:

$$
\mathrm{Cu}^{2+}+\operatorname{HMoxi}^{0} \leftrightarrow[\mathrm{Cu}(\mathrm{HMoxi})]^{2+}
$$

with the maximum concentration at $\mathrm{pH}=4$. This complex upon increasing $\mathrm{pH}$, binds another molecule of moxifloxacin and gives $\left[\mathrm{Cu}(\mathrm{HMoxi})_{2}\right]^{2+}$ complex $\left(\mathrm{Cu}(\mathrm{Moxi})_{2} \mathrm{H}_{2}\right.$ on the distribution diagram) with maximum concentration at $\mathrm{pH} \sim 6$, by the reaction:

$$
[\mathrm{Cu}(\text { HMoxi })]^{2+}+\mathrm{HMoxi}^{0} \leftrightarrow\left[\mathrm{Cu}(\text { HMoxi })_{2}\right]^{2+}
$$

Figure 3. Distribution diagram of $\mathrm{Cu}-$ moxifloxacin species at ligand-to-metal concentration ratio $2: 1$ and total metal concentration $1.0 \mathrm{mmol} / \mathrm{L}$.

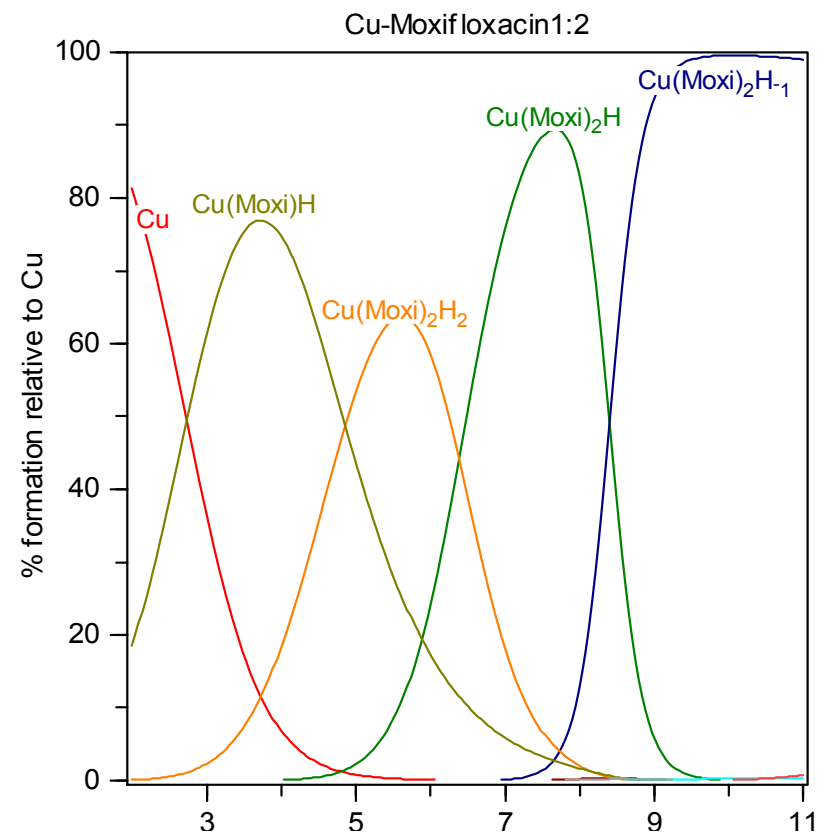

Figure 4. Distribution diagram of Ni-moxifloxacin species at ligand-to-metal concentration ratio $2: 1$ and total metal concentration $1.0 \mathrm{mmol} / \mathrm{L}$.

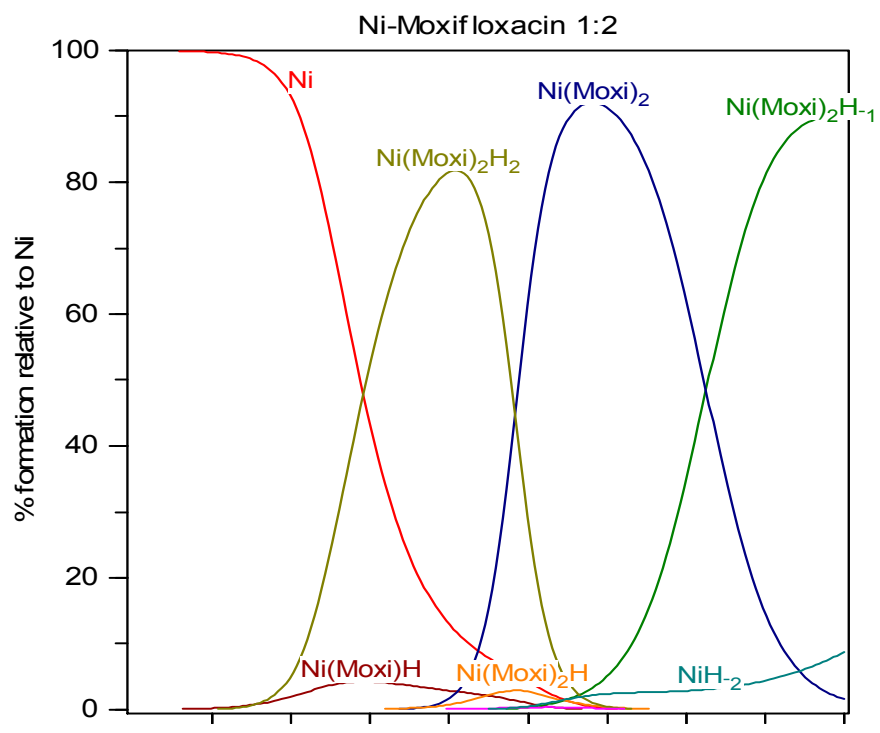


Figure 5. Distribution diagram of Zn-moxifloxacin species at ligand-to-metal concentration ratio $2: 1$ and total metal concentration $1.0 \mathrm{mmol} / \mathrm{L}$.

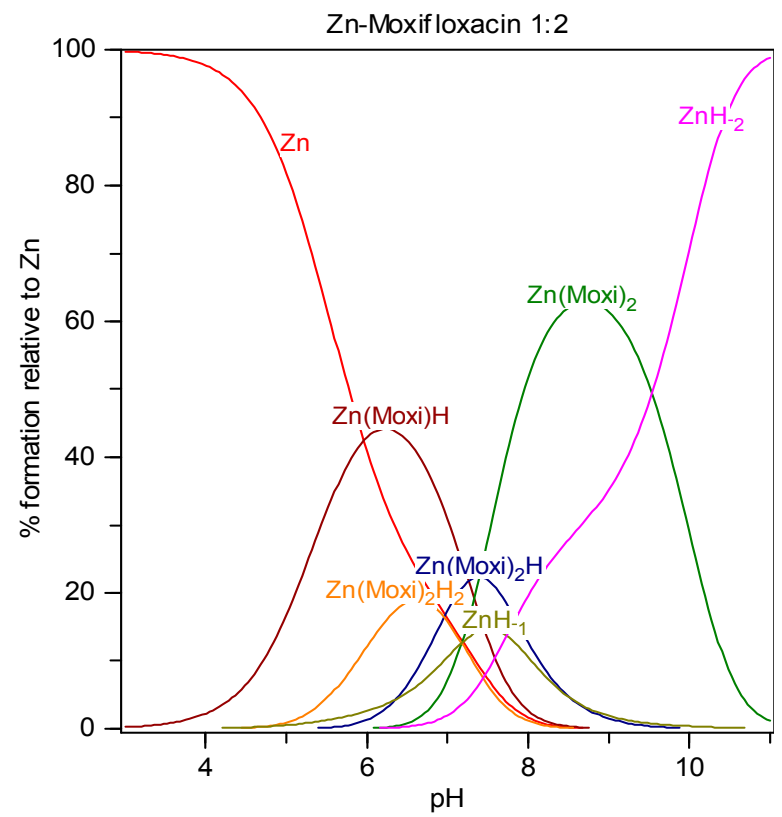

At $\mathrm{pH}$ values above 6.5 this complex releases protons and gives the mixed complex $[\mathrm{Cu} \text { (HMoxi)Moxi }]^{+}\left(\mathrm{Cu}\right.$ (Moxi) ${ }_{2} \mathrm{H}$ on the distribution diagram) with a maximum concentration at $\mathrm{pH}$ values close to physiological. Further $\mathrm{pH}$ increases lead to the release of another proton and formation of $\left[\mathrm{Cu}(\mathrm{Moxi})_{2}(\mathrm{OH})\right]$ species $\left(\mathrm{Cu}(\mathrm{Moxi})_{2} \mathrm{H}_{-1}\right.$ on the distribution diagram) at $\mathrm{pH}>8$. The complex $\left[\mathrm{Cu}(\mathrm{Moxi})_{2}\right]^{0}$ is a minor species between $\mathrm{pH}$ value $7.5-8.5$. The overall complex reaction follows the scheme:

$$
\begin{aligned}
\mathrm{Cu}^{2+}+\text { HMoxi }^{0} & \rightarrow[\mathrm{Cu}(\text { HMoxi })]^{2+}+\mathrm{HMoxi}^{0} \rightarrow \\
& \rightarrow\left[\mathrm{Cu}(\text { HMoxi })_{2}\right]^{+} \stackrel{-\mathrm{H}^{+}}{\longrightarrow}\left[\mathrm{Cu}(\text { Moxi })_{2}\right]^{0} \stackrel{+\mathrm{H}_{2 O}}{\longrightarrow}\left[\mathrm{Cu}(\text { Moxi })_{2}\right]\left(\mathrm{H}_{2} \mathrm{O}\right) \stackrel{-\mathrm{H}^{+}}{\longrightarrow} \\
& \rightarrow\left[\mathrm{Cu}(\text { Moxi })_{2}(\mathrm{OH})\right]^{-}
\end{aligned}
$$

Copper(II) ion exhibits characteristic coordination numbers 4, 5 and 6 . In the $\left[\mathrm{Cu}(\mathrm{HMoxi})_{2}\right]^{2+}$ complex, according to X-ray data [35], moxifloxacin acts as a bidentate O,O-ligand with probable formation of a six-membered ring by the 4-keto and 3-carboxyl oxygens [36-40]. It may be assumed that one or two additional coordination sites in the copper coordination sphere are occupied with water molecules. One of water molecules is more strongly bound to $\mathrm{Cu}^{2+}$ ion and is subject to hydrolysis upon increasing the $\mathrm{pH}$. The other water molecule hydrolyzes at $\mathrm{pH}>11$ and this leads to the onset of precipitation.

Figure 4 represents the distribution of moxifloxacin species in solution in the presence of nickel. Obvious dominant species are those of the $\mathrm{ML}_{2}$ type. $\left[\mathrm{Ni}(\mathrm{HMoxi})_{2}\right]^{2+}$ complex $\left(\mathrm{Ni}(\mathrm{Moxi})_{2} \mathrm{H}_{2}\right.$ on the distribution diagram) forms in the $\mathrm{pH}$ 4-7 range with the maximum concentration at $\mathrm{pH}=6$ and neutral complex $\left[\mathrm{Ni}(\mathrm{Moxi})_{2}\right]^{0}$ in $\mathrm{pH}$ range $6-10$ with maximum concentration at $\mathrm{pH}=8$. The complex $\left[\mathrm{Ni}(\mathrm{Moxi})_{2}\right]^{0}$ is very stable in the $7.0-9.0 \mathrm{pH}$ range and is probably formed in plasma under physiological conditions. The complexation behavior of moxifloxacin toward nickel is important for understanding the antibacterial action of the drug against metal-dependent microorganisms. For example, Helicobacter pylori (H. pylori) is a common human pathogen responsible for various 
gastric diseases. This bacterium produces urease and hydrogenase to survive in the acidic environment of the stomach. Nickel is an essential cofactor for urease and hydrogenase. H. pylori has to uptake sufficient nickel ions [41] for the maturation of urease, and on the other hand, to prevent the toxic effects of excessive nickel ions. Moxifloxacin was recently found to be effective against $H$. pylori. By binding the $\mathrm{Ni}^{2+}$ into a strong Ni-Moxi complex, moxifloxacin acts as safe and strong Helicobacter pylori eradicator [42].

The distribution diagram of species in the $\mathrm{Zn}^{2+}$-moxifloxacin system, for the concentration ratio $[\mathrm{Moxi}] /[\mathrm{Zn}]=2: 1$ is shown in Figure 5. As can be seen from Figure 5 the dominating complexes in a wide $\mathrm{pH}$ range are $[\mathrm{Zn}(\mathrm{HMoxi})]^{2+}\left(\mathrm{Zn}(\right.$ Moxi)H on the distribution diagram $)$ and $\left[\mathrm{Zn}(\mathrm{Moxi})_{2}\right]^{0}$, with the maximum concentrations at $\mathrm{pH} 6$ and $c a$. 9, respectively. These complexes may be formed via the same reaction mechanism as in case of copper and nickel ions. In the $\mathrm{pH}$ range 5.5-8.5 the complexes $\left[\mathrm{Zn}(\mathrm{HMoxi})_{2}\right]^{2+}\left(\mathrm{Zn}(\mathrm{Moxi})_{2} \mathrm{H}_{2}\right.$ on the distribution diagram) and $\left[\mathrm{Zn}(\mathrm{HMoxi})(\text { Moxi) }]^{+}\left(\mathrm{Zn}(\mathrm{Moxi})_{2} \mathrm{H}\right.\right.$ on the distribution diagram) occur to a lesser extent. Hydrolytic species of $\mathrm{Zn}^{2+}$ disturb the complexation considerably. Micro-colloidal precipitated $\mathrm{ZnH}_{-2}$ is dominant at $\mathrm{pH}>9$. Similar species distribution results were obtained for the other M-FQ systems.

\subsection{Fluorescence Measurements}

Spectrofluorimetric titrations were carried out by addition of known quantities of metal ion (concentration range $(0-1) \times 10^{-3} \mathrm{~mol} / \mathrm{L}$ ) to $2 \times 10^{-5} \mathrm{~mol} / \mathrm{L}$ buffered solutions of the ligand.

The wavelenght of excitation was $292 \mathrm{~nm}$ (for levofloxacin). Fluorescence spectra of levofloxacin in the absence and the presence of copper ion are presented in Figure 6. From the figure a decrease of fluorescence intensity upon addition of copper ion can be seen. The maximum emission of levofloxacin occurs at $482 \mathrm{~nm}$ and it shifts hypsochromically slightly upon addition of copper.

Figure 6. Fluorescence emission spectrum of levofloxacin $\left(2 \times 10^{-5} \mathrm{~mol} / \mathrm{L}, \lambda_{\mathrm{ex}}=292 \mathrm{~nm}\right)$ in aqueous solution at $\mathrm{pH} 7.4$ in the presence of $\mathrm{Cu}(\mathrm{II})$ ions (concentration range of $\mathrm{Cu}$ ion: $\left.(0-1) \times 10^{-3} \mathrm{~mol} / \mathrm{L}\right)$.

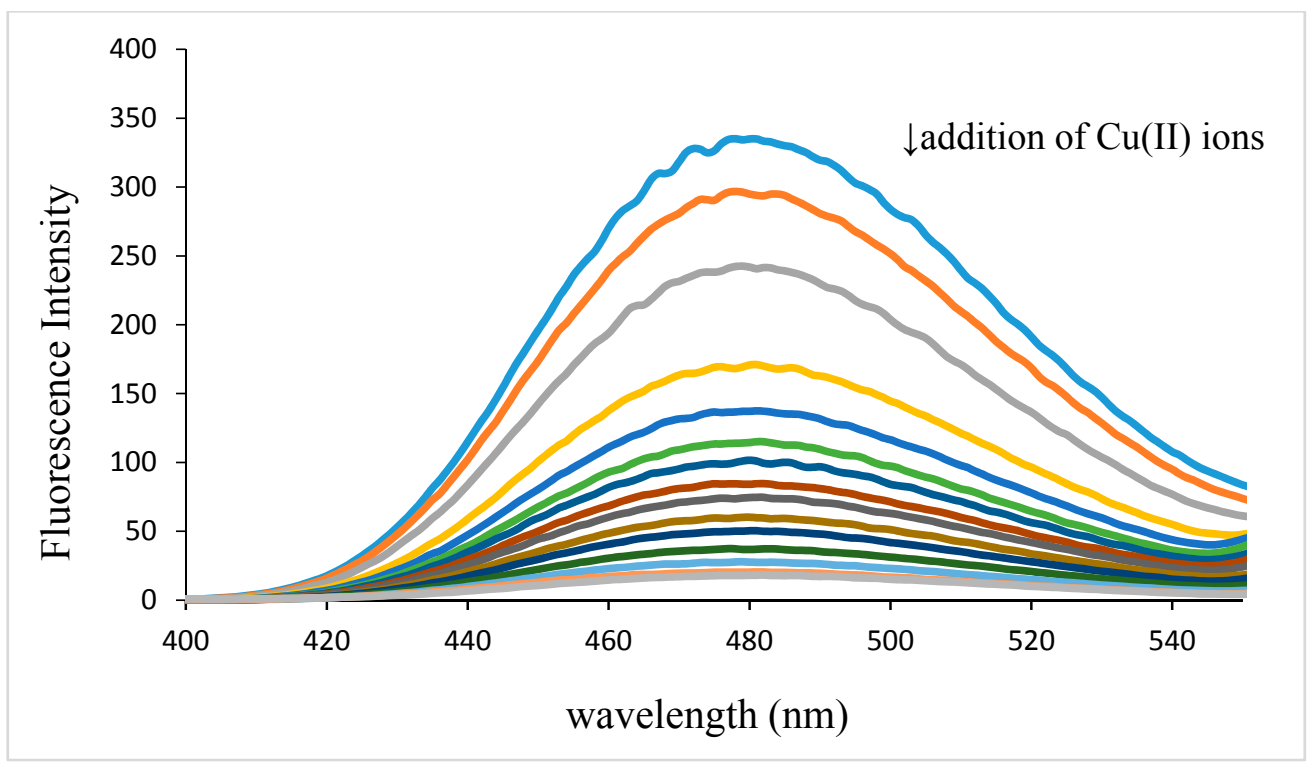


To examine the fluorescence quenching mechanism a Stern-Volmer plot was used and presented in Figure 7.

$$
\frac{\mathrm{F}_{0}}{\mathrm{~F}}=1+K_{S V}[M]
$$

where $\mathrm{F}_{0}$ and $\mathrm{F}$ are the fluorescence intensity in the absence and the presence of the quencher, respectively and $[\mathrm{M}]$ is the concentration of the metal ion [43]. From the slope of the Stern-Volmer plot, the Stern-Volmer constant can be determined. The obtained value was $\mathrm{K}_{\mathrm{SV}}=1.82 \times 10^{4}$ or $\log \mathrm{K}_{\mathrm{SV}}=4.26$. Fluorescence quenching typically occurs through either static or dynamic quenching mechanisms. The static quenching results in a linear relationship between $\left(\mathrm{F}_{0} / \mathrm{F}\right)$ and concentration of metal ion. This result suggests that levofloxacin fluorescence quenching in the precense of copper ion was probable static quenching as a result of the formation of a non-fluorescent complex between the fluorophore and the quencher.

Figure 7. Stern-Volmer plot for the quenching of levofloxacin by copper ion.

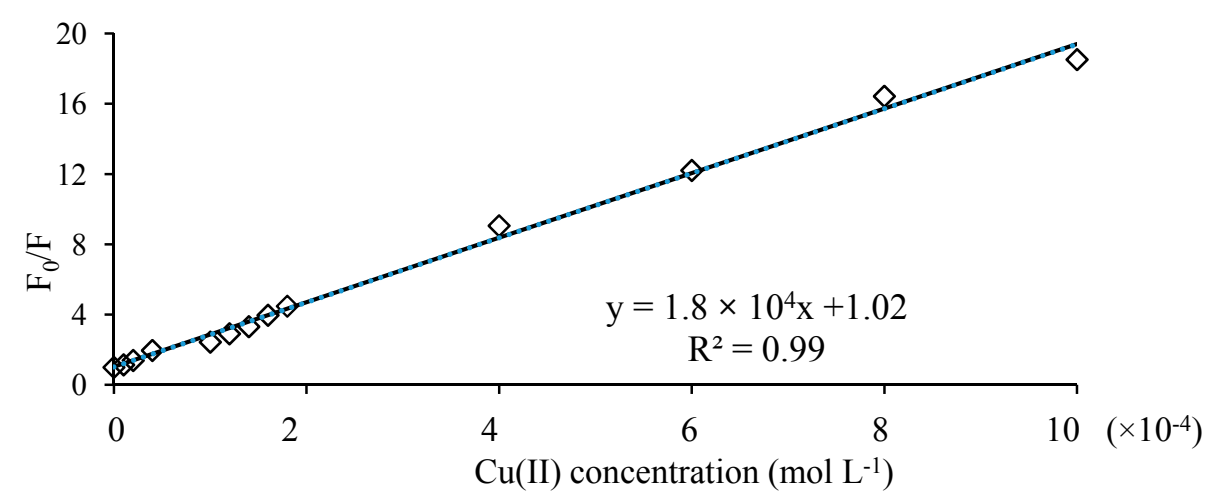

Stability constant determination. The complexation of a metal ion $\mathrm{Cu}^{2+}$ by a ligand levofloxacin in solution can be represented by the cumulative equilibria:

$$
\begin{gathered}
\mathrm{M}+\mathrm{L} \leftrightarrow \mathrm{ML} \\
\mathrm{M}+2 \mathrm{~L} \leftrightarrow \mathrm{ML}_{2}
\end{gathered}
$$

with the association constant $\mathrm{K}$ :

$$
\mathrm{K}_{\mathrm{n}}=\frac{[\mathrm{ML}]}{[\mathrm{M}][\mathrm{L}]^{n}} ; \mathrm{n}=1,2
$$

expressing the degree of stability of the complex in the given solvent and temperature conditions. The stability constants of the formed complexes can be calculated from the double reciprocal plot:

For 1:1 complex:

$$
\frac{1}{F_{0}-F}=\frac{1}{\left(F_{O}-F_{\infty}\right) K_{1} C_{M}}+\frac{1}{F_{O}-F_{\infty}}
$$

And for 1:2 complex:

$$
\frac{1}{F_{0}-F}=\frac{1}{\left(F_{O}-F_{\infty}\right) K_{2} C_{M}^{2}}+\frac{1}{F_{O}-F_{\infty}}
$$


where $\mathrm{F}_{0}$ and $\mathrm{F}$ are the fluorescence intensity of ligand in the absence of metal ion and fluorescence intensity of solution at each metal concentration, respectively $[44,45] . \mathrm{F}_{\infty}$ is the fluorescence intensity when fluorescence of the solution remains constant with further addition of metal ion. $\mathrm{K}_{1}$ and $\mathrm{K}_{2}$ are the stability constants of the formed complexes. When $1 /\left(F_{0}-F\right)$ is plotted against $C_{M}{ }^{-1}$ or $C_{M}{ }^{-2}$ (Figure 8 ) the stability constant is calculated by the ratio intercept/slope. The formation stability constant for these complexes calculated to be $\log K_{1}=4.23$ and $\log K_{2}=8.19$ or $\log \beta_{1}=4.23$ and $\log \beta_{2}=12.42$. These values are very close to those calculated by potentiometric and spectrophotometric measurements.

Figure 8. Double reciprocal plot obtained from $1 /\left(\mathrm{F}-\mathrm{F}_{0}\right.$ ) plotted against: (a) $1 / \mathrm{C}_{\mathrm{M}}$ and $(\mathbf{b}) 1 / \mathrm{C}_{\mathrm{M}}{ }^{2}$.

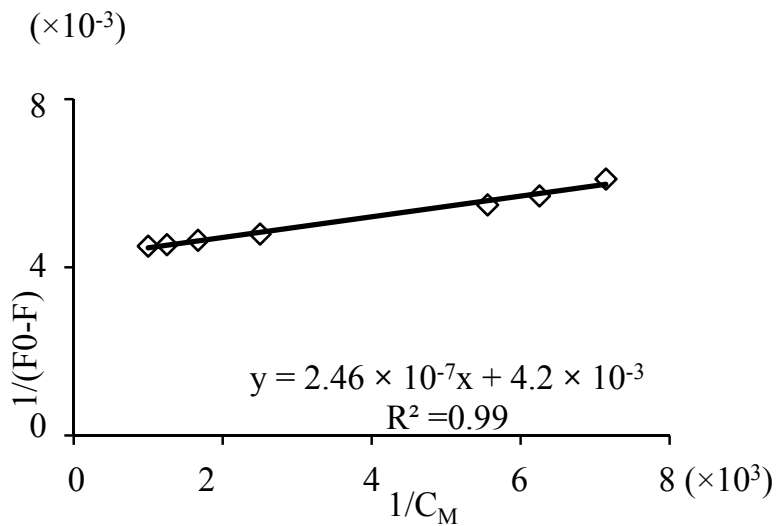

(a)

$$
\left(\times 10^{-3}\right)
$$

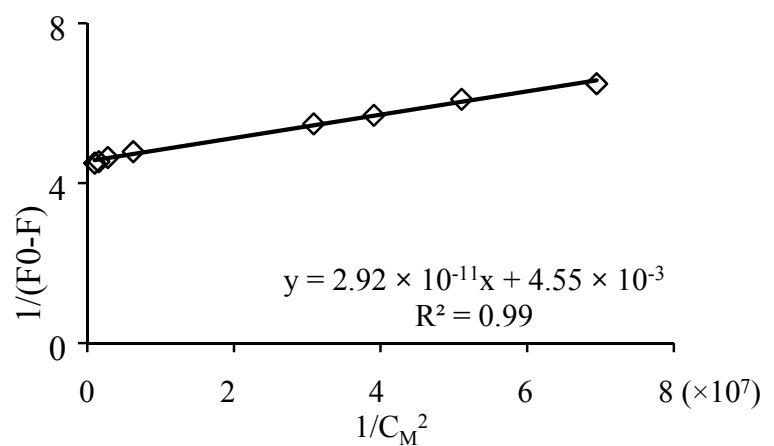

(b)

Consideration of the Inner Filter Effect

UV absorbance spectra demonstrate that FQs and their metal complexes strongly absorb at $292 \mathrm{~nm}$, the excitation wavelenght of FQs. The attenuation of the excitation beam due to such absorption results in a fluorescence intensity decrease know as the inner filter effect [46]. Since absorbtion is high correction was aplied to all our fluorescence data. The corection factor CF was calculated according to Parker and Barnes equation [47]:

$$
C F=\frac{F_{0}}{F}=\frac{2.303 A_{x} \Delta l_{x}}{10^{-A_{x} l_{x}}\left(10^{A_{x} \frac{\Delta l_{x}}{2}}-10^{-A_{x} \frac{\Delta l_{x}}{2}}\right.}
$$

where $F_{0}$ is the corrected fluorescence, $F$ is the observed fluorescence and $A_{x}$ is the optical density of the solution at excitation wavelength; $l_{\mathrm{x}}$ and $\Delta l_{\mathrm{x}}$ are geometrical parameters of the fluorimetric cell. The $l_{\mathrm{x}}$ was calculated according to formula $l_{\mathrm{x}}=\left(1-\Delta l_{\mathrm{x}}\right) / 2 . \Delta l_{\mathrm{x}}$ was set as $0.250 \mathrm{~cm}$ corresponding to $10 \mathrm{~nm}$ bandwidth [48]. The calculated correction factor was in the range 1.50-1.73.

\section{5. $H^{1}$-NMR Measurements}

To extend the speciation study some NMR spectra of the studied systems were recorded. The NMR experimental conditions were so chosen to make speciation unambiguous. Proton NMR spectra of levofloxacin and $\mathrm{Zn}^{2+}+$ levofloxacin at different molar ratios are shown in Figure 9. 
Figure 9. ${ }^{1} \mathrm{H}-\mathrm{NMR}$ spectra of $\mathrm{Zn}(\mathrm{II})$-levofloxacin complexes at various mole ratios of the ligand and zinc salt in DMSO- $\mathrm{d}_{6}$ solution recorded at $200 \mathrm{MHz}$.

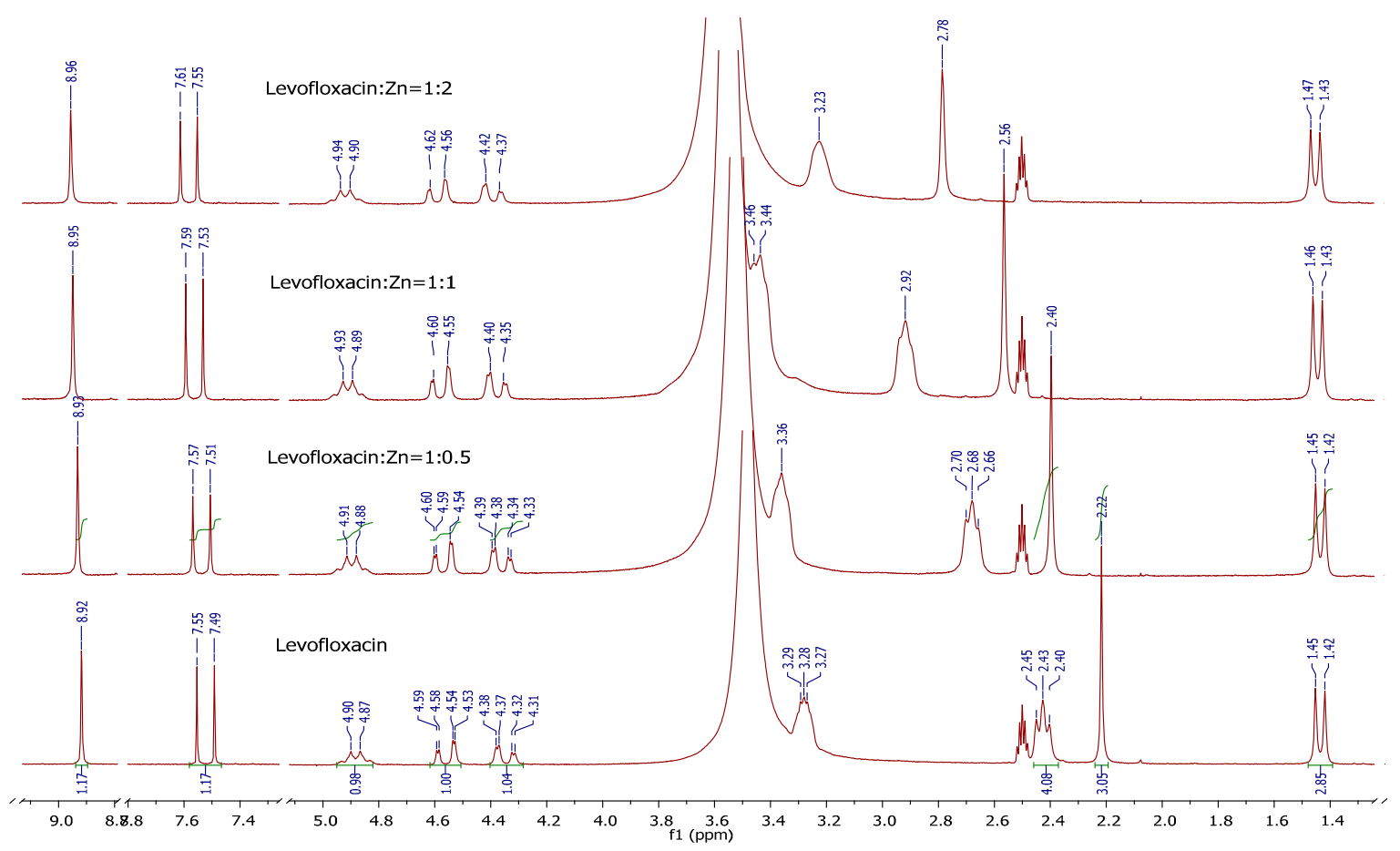

The signals for aryl protons (doublet at 7.52 (C-5) and singlet at $8.92 \mathrm{ppm}$ (C-2)), oxazine protons (4.31-4.90 ppm) and methyl group protons attached to oxazine ring (doublet at $1.43 \mathrm{ppm}$ ) are practically unchanged after the addition of different amounts of zinc(II)-chloride. This indicates that they are situated far from the binding site. However, two groups of the piperazine signals as well as the methyl protons of the piperazine nitrogen appeared at significantly higher $\delta$-values in all ${ }^{1} \mathrm{H}$-NMR spectra of the zinc(II)-complexes. This strong downfield shift for the piperazine methyl group (0.56 ppm), 3',5'-piperazine protons $(0.79 \mathrm{ppm})$ and 2',6'-piperazine protons (more than $0.3 \mathrm{ppm}$, overlapped with the water peak) indicates that the piperazine nitrogen atoms are coordinated to the zinc (Figure 9). A tentative structure of the complex may be represented as in Figure 10.

Figure 10. Proposed structure for $\mathrm{Zn}(\mathrm{II})$-levofloxacin complex.

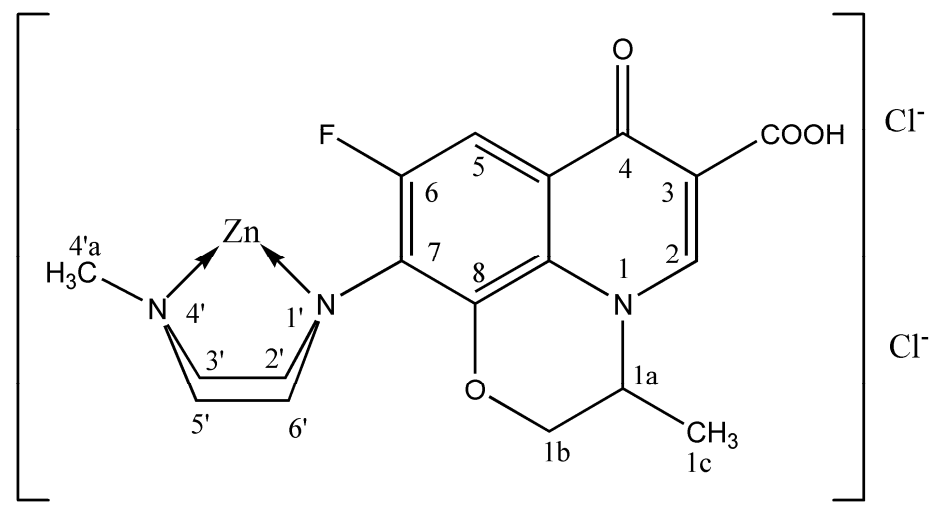

Addition of $\mathrm{Zn}^{2+}$ into a $\mathrm{D}_{2} \mathrm{O}$ solution of levofloxacin at $\mathrm{pH}=6.0$ (mole ratio: $\mathrm{Zn}$ to Levo= $1: 1$ and 2:1) produces C-2 proton shift toward lower field (Table 5). Most other proton signals are also shifted 
downfield in comparison with free ligand protons. It may be concluded that zinc is coordinated to the carboxylate and 4-carbonyl oxygen in $\mathrm{D}_{2} \mathrm{O}$ as reported in many papers [36-40]. Thus, the binding sites of $\mathrm{Zn}^{2+}$ ion in $\mathrm{D}_{2} \mathrm{O}$ are different from those in DMSO- $d_{6}$. The difference may be attributed to the different polarity of these molecules.

Table 5. ${ }^{1} \mathrm{H}-\mathrm{NMR}$ chemical shifts of Levo and Levo $+\mathrm{Zn}^{2+}$ (concentration ratio $1: 1$ at $\mathrm{pH}=6.0$ ).

\begin{tabular}{cccc}
\hline Levo-proton & $\boldsymbol{\delta}_{\text {(free) }}$ & $\boldsymbol{\delta}_{\text {(complex) }}$ & $\Delta \boldsymbol{\delta}^{\mathbf{a}}$ \\
\hline H-2 & 8.34 & 8.51 & 0.17 \\
H-5 & 7.24 & 7.25 & 0.01 \\
H-1a, 1b & $4.36-4.61$ & $4.38-4.64$ & 0.01 \\
H-3', 5' & 3.50 & 3.61 & 0.11 \\
H-2', 6' & 3.38 & 3.46 & 0.08 \\
H-4'a & 2.95 & 2.99 & 0.04 \\
H-1c & 1.44 & 1.43 & 0.01 \\
\hline \multicolumn{5}{c}{${ }^{\mathrm{a}} \Delta \delta=\delta_{\text {(complex) }}-\delta_{\text {(fre)). }}$}
\end{tabular}

\subsection{ESI-MS Measurements}

To further confirm the speciation derived from potentiometric and spectrophotometric measurements ESI-MS measurements were made on fluoroquinolone-metal ion solutions. The experimental conditions were adjusted in such a way that the fragmentation is minimal. Several time repeated measurements resulted in nearly the same spectra, indicating that the obtained signals belong to species formed in solutions rather than in gas plasma. The most intensive signals can be attributed to the 1:1 and 1:2 (metal to ligand) complexes. Signals arising from fragmentation can be explained either by $\mathrm{CO}_{2}$ or $\mathrm{H}_{2} \mathrm{O}$ loss. Loss of $\mathrm{HF}$ was not observed. The ESI-MS data of M-FQ solutions with FQ to metal concentration ratio $2: 1$ at $\mathrm{pH} 4.5$ show evidence to formation of the complex $\mathrm{M}(\mathrm{FQ})$ and $\mathrm{M}(\mathrm{FQ})_{2}$ as shown in Tables 6-8, and in Figure 11.

Table 6. Experimental and theoretical $\mathrm{m} / \mathrm{z}$ values of ESI-MS spectra in Copper-fluoroquinolone solution at $\mathrm{pH}=4.5 ;\left((\mathrm{m} / \mathrm{z})_{\mathrm{e}}\right.$ and $(\mathrm{m} / \mathrm{z})_{\mathrm{t}}$ denote experimentally determined and calculated value, respectively).

\begin{tabular}{|c|c|c|c|c|c|c|}
\hline \multirow{3}{*}{ Fluoroquinolone } & \multicolumn{6}{|c|}{ Complex } \\
\hline & \multicolumn{2}{|c|}{${ }[\mathbf{M L}]^{+}$} & \multicolumn{2}{|c|}{$\left[\mathbf{M L}_{2}\right]^{+}$} & \multicolumn{2}{|c|}{$\left[\mathbf{M}_{2} \mathbf{L}_{3}\right]^{+}$} \\
\hline & $(m / z)_{\mathrm{e}}$ & $(m / z)_{t}$ & $(m / z)_{\mathrm{e}}$ & $(m / z)_{t}$ & $(m / z)_{\mathrm{e}}$ & $(m / z)_{t}$ \\
\hline Moxifloxacin & 464.3 & 463.9 & 865.0 & 864.8 & 1327.7 & 1327.3 \\
\hline Ofloxacin & 425.1 & 424.9 & 784.2 & 784.2 & - & - \\
\hline Levofloxacin & 425.0 & 424.9 & - & - & - & - \\
\hline Ciprofloxacin & - & - & 724.1 & 724.2 & - & - \\
\hline
\end{tabular}


Table 7. Experimental and theoretical $\mathrm{m} / \mathrm{z}$ values of ESI-MS spectra in Zinc-fluoroquinolone solution at $\mathrm{pH}=4.5$.

\begin{tabular}{ccccc}
\hline & \multicolumn{4}{c}{ Complex } \\
\cline { 2 - 5 } Fluoroquinolone & \multicolumn{2}{c}{$\left[\mathbf{M L}^{+}\right.$} & \multicolumn{2}{c}{$\left[\mathbf{M L}_{2}\right]^{+}$} \\
\cline { 2 - 5 } & $(\boldsymbol{m} / \mathbf{z})_{\mathbf{e}}$ & $(\boldsymbol{m} / \mathbf{z})_{\mathbf{t}}$ & $(\boldsymbol{m} / \mathbf{z})_{\mathbf{e}}$ & $(\boldsymbol{m} / \mathbf{z})_{\mathbf{t}}$ \\
\hline Moxifloxacin & 466.1 & 465.7 & - & - \\
Ofloxacin & 425.2 & 424.9 & - & - \\
Levofloxacin & - & - & 786.4 & 786.0 \\
Ciprofloxacin & - & - & 726.0 & 725.9 \\
\hline
\end{tabular}

Table 8. Experimental and theoretical $\mathrm{m} / \mathrm{z}$ values of ESI-MS spectra in Nickel-fluoroquinolone solution at $\mathrm{pH}=4.5$.

\begin{tabular}{ccccc}
\hline & \multicolumn{4}{c}{ Complex } \\
\cline { 2 - 5 } Fluoroquinolone & \multicolumn{2}{c}{$\left[\mathbf{M L}^{+}\right.$} & \multicolumn{2}{c}{$\left[\mathbf{M L}_{2}\right]^{+}$} \\
\cline { 2 - 5 } & $(\boldsymbol{m} / \mathbf{z})_{\mathbf{e}}$ & $(\boldsymbol{m} / \mathbf{z})_{\mathbf{t}}$ & $(\boldsymbol{m} / \mathbf{z})_{\mathbf{e}}$ & $(\mathbf{m} / \mathbf{z})_{\mathbf{t}}$ \\
\hline Moxifloxacin & 459.2 & 459.0 & 859.6 & 859.9 \\
Ofloxacin & 419.5 & 419.2 & - & - \\
Levofloxacin & - & - & 778.9 & 779.3 \\
Ciprofloxacin & 389.6 & 389.1 & 719.5 & 719.4 \\
\hline
\end{tabular}

Figure 11. ESI-MS spectrum of $\mathrm{Cu}$-moxifloxacin solution at $\mathrm{pH}=4.5$.

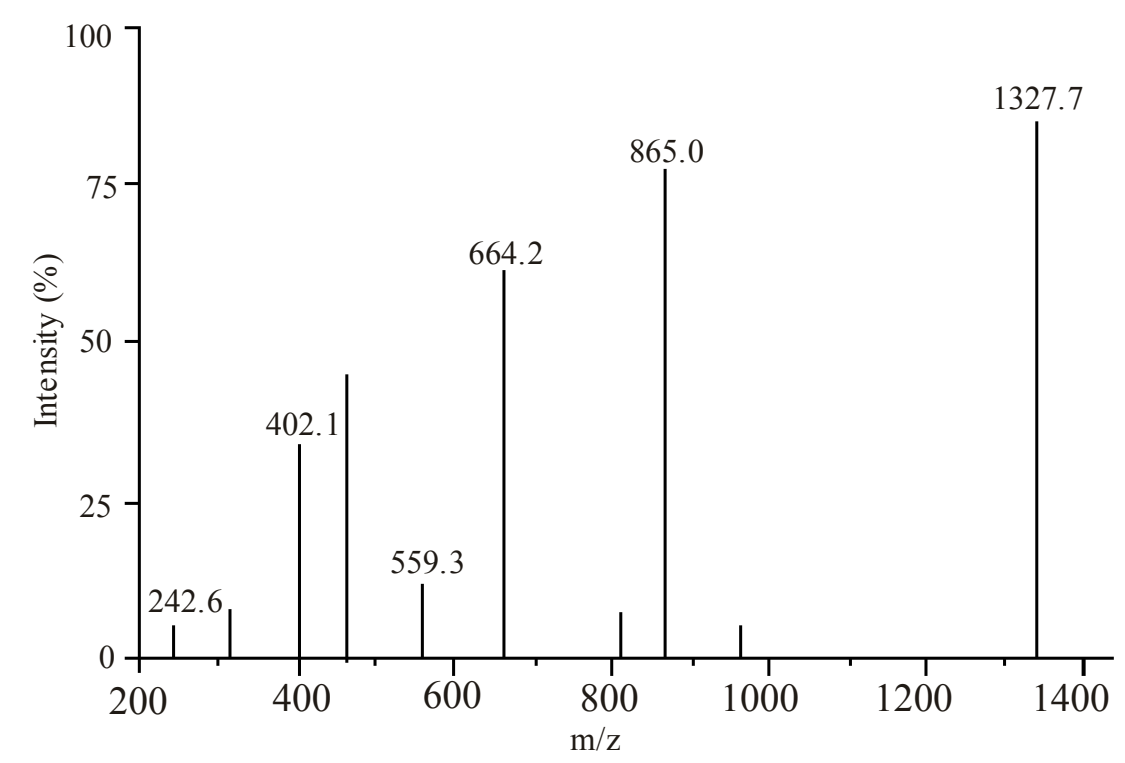

2.7. Influence of Fluoroquinolones on Bio-Speciation of Copper, Nickel and Zinc Ions in Human Blood Plasma

The LMW bio-distributions of $\mathrm{Cu}(\mathrm{II}), \mathrm{Zn}$ (II) and $\mathrm{Ni}$ (II) ions in the presence of fluoroquinolone in blood plasma were computed using the HySS2009 program. The total concentrations of physiological plasma ligands and metals were as described in our previous paper [16]. Average maximum concentration of quinolones in human plasma is $c a .2 \times 10^{-5} \mathrm{~mol} / \mathrm{L}$. 
Table 9. Calculated bio-distribution of dominant $\mathrm{Cu}(\mathrm{II})$ species (\%) in human blood plasma in the presence of fluoroquinolones.

\begin{tabular}{|c|c|c|c|c|}
\hline \multirow{3}{*}{ Cu-LMW Species } & \multicolumn{4}{|c|}{ Concentration of Fluoroquinolone $(\mathrm{mol} / \mathrm{L})$} \\
\hline & $\mathbf{0}$ & $1 \times 10^{-5}$ & $1 \times 10^{-4}$ & $1 \times 10^{-3}$ \\
\hline & \multicolumn{4}{|c|}{ Moxifloxacin } \\
\hline CuCisHis & 25.0 & 23.9 & 23.9 & 22.7 \\
\hline CuHCisHis & 15.8 & 15.1 & 15.1 & 14.3 \\
\hline $\mathrm{CuHis}_{2}$ & 10.7 & 10.2 & 10.2 & 9.7 \\
\hline CuHisSer & 6.8 & 6.5 & 6.5 & 6.1 \\
\hline CuHisThr & 6.0 & 5.8 & 5.8 & 5.5 \\
\hline \multirow[t]{2}{*}{ CuHHisLys } & 4.5 & 4.3 & 4.3 & 4.1 \\
\hline & \multicolumn{4}{|c|}{ Ciprofloxacin } \\
\hline CuCisHis & 25.0 & 25.0 & 24.9 & 20.8 \\
\hline CuHCisHis & 15.8 & 15.7 & 15.7 & 13.2 \\
\hline $\mathrm{CuHis}_{2}$ & 10.7 & 10.7 & 10.7 & 8.9 \\
\hline CuHisSer & 6.8 & 6.7 & 6.7 & 5.6 \\
\hline CuHisThr & 6.0 & 6.0 & 6.3 & 5.0 \\
\hline \multirow[t]{2}{*}{ CuHHisLys } & 4.5 & 4.5 & 4.5 & 3.7 \\
\hline & \multicolumn{4}{|c|}{ Ofloxacin } \\
\hline CuCisHis & 25.0 & 25.0 & 25.0 & 25.0 \\
\hline CuHCisHis & 15.8 & 15.8 & 15.8 & 15.8 \\
\hline $\mathrm{CuHis}_{2}$ & 10.7 & 10.7 & 10.7 & 10.7 \\
\hline CuHisSer & 6.8 & 6.8 & 6.8 & 6.7 \\
\hline CuHisThr & 6.0 & 6.0 & 6.0 & 6.0 \\
\hline CuHHisLys & 4.5 & 4.5 & 4.5 & 4.5 \\
\hline CuCisHis & 25.0 & 25.0 & 25.0 & 25.0 \\
\hline \multirow[t]{2}{*}{$\mathrm{CuHCisHis}$} & 15.8 & 15.8 & 15.8 & 15.8 \\
\hline & \multicolumn{4}{|c|}{ Levofloxacin } \\
\hline $\mathrm{CuHis}_{2}$ & 10.7 & 10.7 & 10.7 & 10.7 \\
\hline CuHisSer & 6.8 & 6.8 & 6.8 & 6.7 \\
\hline CuHisThr & 6.0 & 6.0 & 6.0 & 6.0 \\
\hline CuHHisLys & 4.5 & 4.5 & 4.5 & 4.4 \\
\hline
\end{tabular}

\subsubsection{Copper in Human Blood Plasma Model}

The concentration of free copper is taken as $1 \times 10^{-19} \mathrm{~mol} / \mathrm{L}$. The major LMW complexes of copper ion in plasma at normal physiological conditions (no exogenous ligand addition) were computed and are shown in Table 9 (first column). At ligand concentrations of less than $1 \times 10^{-4} \mathrm{~mol} / \mathrm{L}$ the fraction of main copper complexes remains unchanged. In the case of ciprofloxacin, however, a small change in the fraction of dominant $\mathrm{Cu}$-LMW species at ligand concentrations $1 \times 10^{-5}-1 \times 10^{-4} \mathrm{~mol} / \mathrm{L}$ is seen (Table 9). With increasing ligand concentration to $1 \times 10^{-3} \mathrm{~mol} / \mathrm{L}$ only moxifloxacin and ciprofloxacin influence the fraction of $\mathrm{Cu}-\mathrm{LMW}$ species considerably. Thus, these fluoroquinolones appear as competitive ligands to amino acids. Upon further increasing the ligands concentration to $1 \times 10^{-2} \mathrm{~mol} / \mathrm{L}$ fractions of main LMW complexes continue to decrease until, in the extreme case, the complexes of $\mathrm{Cu}-\mathrm{FQ}$ appear. Normal level of FQs in blood plasma after a single dose of a $500 \mathrm{mg}$ tablet 
administration is $c a \cdot 10^{-5} \mathrm{~mol} / \mathrm{L}$ [49]. This peak concentration lasts for about $2-3 \mathrm{~h}$ and then begins to fall. Considering the plasma life of FQs is long enough to establish a local equilibrium, competitive reactions between LMW complexes of copper ion and FQs may occur. Thus, a fraction of copper may be bound to the FQs. It is well known that metal-FQ complex species alter the properties of the FQ in terms of bioavailability and antimicrobial action [50]. As illustrated in Figure 12, increasing the plasma concentration of FQ increases the fraction of mobilized copper. It may provide an additional explanation of the mechanism of FQ action with respect to the role of essential metal ions.

Figure 12. Dominant Cu-Cipro species in blood plasma in the presence of ciprofloxacin (Cip).

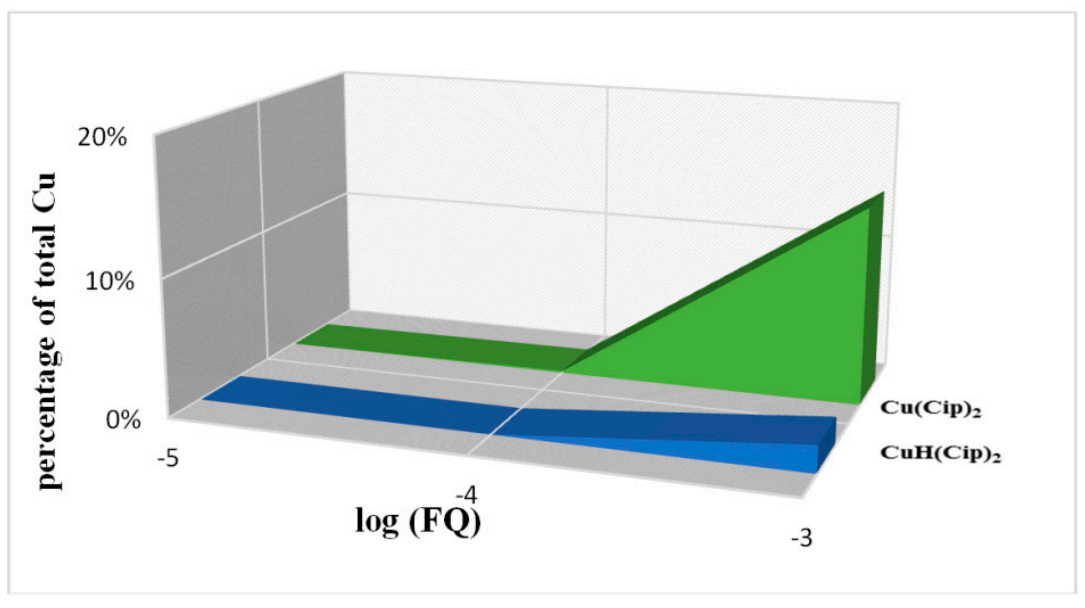

The PMI curves of copper ion with the studied fluoroquinolones are shown in Figure 13. It can be seen that ciprofloxacin has the highest mobilizing effect. The effects of ofloxacin and levofloxacin do not differ significantly.

Figure 13. The effect of fluoroquinolone ligands on plasma mobilization of copper.

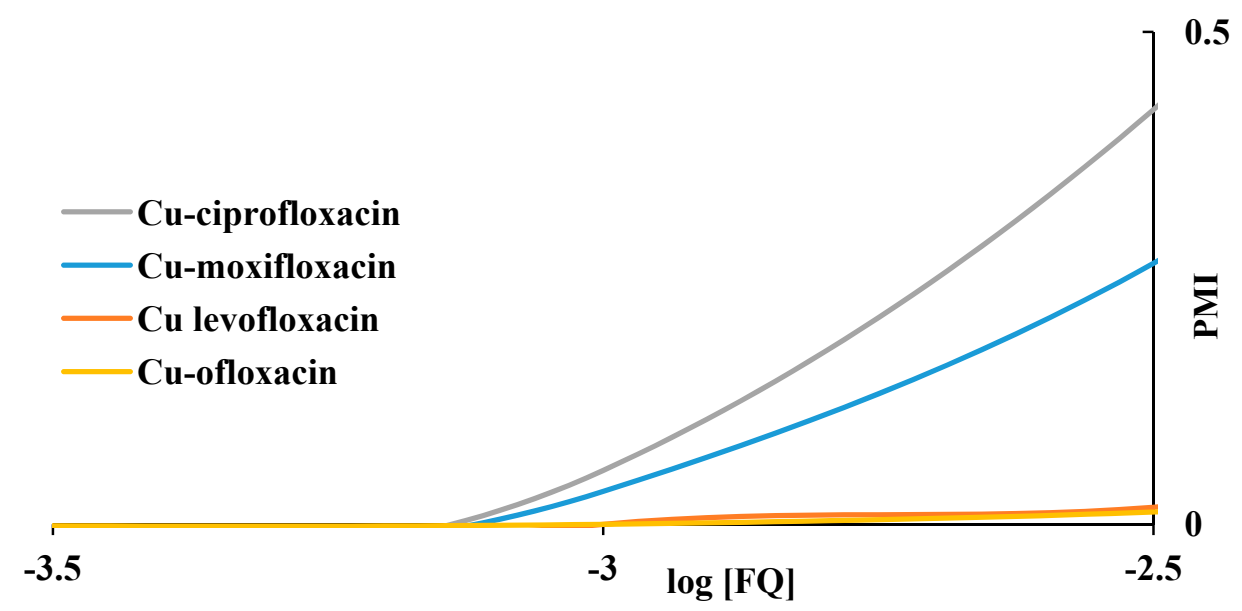

\subsubsection{Nickel in Human Blood Plasma Model}

Earlier works suggested that the major nickel species in blood plasma are $\mathrm{Ni}(\mathrm{His})_{2}, \mathrm{Ni}(\mathrm{Cys})(\mathrm{His})$, $\mathrm{Ni}(\mathrm{Cys})_{2}$ and $\mathrm{Ni}$ (His) [51]. Blood nickel levels of $1 \times 10^{-8} \mathrm{~mol} / \mathrm{L}$ have been reported [52]. The calculated bio-distribution of Ni-LMW species in the absence and in the presence of fluoroquinolones 
is presented in Table 10. As it can be seen from the data, the FQ with the strongest influence on LMW nickel complexes was levofloxacin, even at a concentration of $1 \times 10^{-5} \mathrm{~mol} / \mathrm{L}^{-1}$. The calculated distribution in the presence of moxifloxacin indicates its relatively lower influence on Ni-LMW species, in a wide range of concentrations, compared to $\mathrm{Cu}-\mathrm{LMW}$ species. The effects of these ligands on the biodistribution of Ni-LMW species has the order levofloxacin $>$ ciprofloxacin $>$ ofloxacin $>$ moxifloxacin.

Table 10. Calculated bio-distribution of dominant Ni (II) species (\%) in human blood plasma in the presence of fluoroquinolones.

\begin{tabular}{|c|c|c|c|c|c|}
\hline \multirow{3}{*}{ Ni-LMW Species } & \multicolumn{5}{|c|}{ Concentration of Fluoroquinolone $(\mathrm{mol} / \mathrm{L})$} \\
\hline & $\mathbf{0}$ & $1 \times 10^{-7}$ & $1 \times 10^{-5}$ & $1 \times 10^{-4}$ & $1 \times 10^{-3}$ \\
\hline & \multicolumn{5}{|c|}{ Levofloxacin } \\
\hline $\mathrm{NiHis}_{2}$ & 83.2 & 83.2 & 73.0 & 4.9 & 0.0 \\
\hline NiCysHis & 9.2 & 9.2 & 8.0 & 0.5 & 0.0 \\
\hline $\mathrm{NiCys}_{2}$ & 3.8 & 3.8 & 3.4 & 0.2 & 0.0 \\
\hline NiHis & 2.4 & 2.4 & 2.1 & 0.1 & 0.0 \\
\hline NiHisCit & 1.2 & 1.2 & 1.1 & 0.1 & 0.0 \\
\hline \multirow[t]{2}{*}{ NiCys } & 0.1 & 0.1 & 0.1 & 0.0 & 0.0 \\
\hline & \multicolumn{5}{|c|}{ Ofloxacin } \\
\hline $\mathrm{NiHis}_{2}$ & 83.2 & 83.2 & 79.7 & 17.0 & 0.2 \\
\hline NiCysHis & 9.2 & 9.2 & 8.8 & 1.9 & 0.0 \\
\hline $\mathrm{NiCys}_{2}$ & 3.8 & 3.8 & 3.7 & 0.8 & 0.0 \\
\hline NiHis & 2.4 & 2.4 & 2.3 & 0.5 & 0.0 \\
\hline NiHisCit & 1.2 & 1.2 & 1.2 & 0.2 & 0.0 \\
\hline \multirow[t]{2}{*}{ NiCys } & 0.1 & 0.1 & 0.1 & 0.0 & 0.0 \\
\hline & \multicolumn{5}{|c|}{ Ciprofloxacin } \\
\hline $\mathrm{NiHis}_{2}$ & 83.2 & 83.2 & 77.5 & 9.8 & 0.1 \\
\hline NiCysHis & 9.2 & 9.2 & 8.5 & 1.1 & 0.0 \\
\hline $\mathrm{NiCys}_{2}$ & 3.8 & 3.8 & 3.6 & 0.5 & 0.0 \\
\hline NiHis & 2.4 & 2.4 & 2.2 & 0.3 & 0.0 \\
\hline NiHisCit & 1.2 & 1.2 & 1.1 & 0.1 & 0.0 \\
\hline \multirow[t]{2}{*}{ NiCys } & 0.1 & 0.1 & 0.1 & 0.0 & 0.0 \\
\hline & \multicolumn{5}{|c|}{ Moxifloxacin } \\
\hline $\mathrm{NiHis}_{2}$ & 83.2 & 83.2 & 83.2 & 83.0 & 68.1 \\
\hline NiCysHis & 9.2 & 9.2 & 9.1 & 9.1 & 7.5 \\
\hline $\mathrm{NiCys}_{2}$ & 3.8 & 3.8 & 3.8 & 3.8 & 3.1 \\
\hline $\mathrm{NiHis}$ & 2.4 & 2.4 & 2.5 & 2.4 & 1.9 \\
\hline NiHisCit & 1.2 & 1.2 & 1.2 & 1.1 & 1.0 \\
\hline NiCys & 0.1 & 0.1 & 1.0 & 1.0 & 0.9 \\
\hline
\end{tabular}

The calculated plasma mobilizing index of nickel in the presence of FQs in shown in Figure 14. Levofloxacin shows higher PMI values than the other FQs. This surprisingly high effect may be perhaps be useful in the treatment of $H$. pylori with levofloxacin.

\subsubsection{Zinc in Human Blood Plasma Model}

Since a $35 \%$ of total zinc is rigidly bound to the proteins the total concentration of exchangeable zinc is estimated to be about $1 \times 10^{-6} \mathrm{~mol} / \mathrm{L}$ [5]. Calculated distribution of LMW-Zn species is 
presented in Table 11. At nominal plasma levels, FQs does not exert a significant effect on LMW-Zn fractions. It seems that FQs are not effective competitors to amino acids for $\mathrm{Zn}$ binding.

Figure 14. The effect of fluoroquinolone ligands on plasma mobilization of nickel.

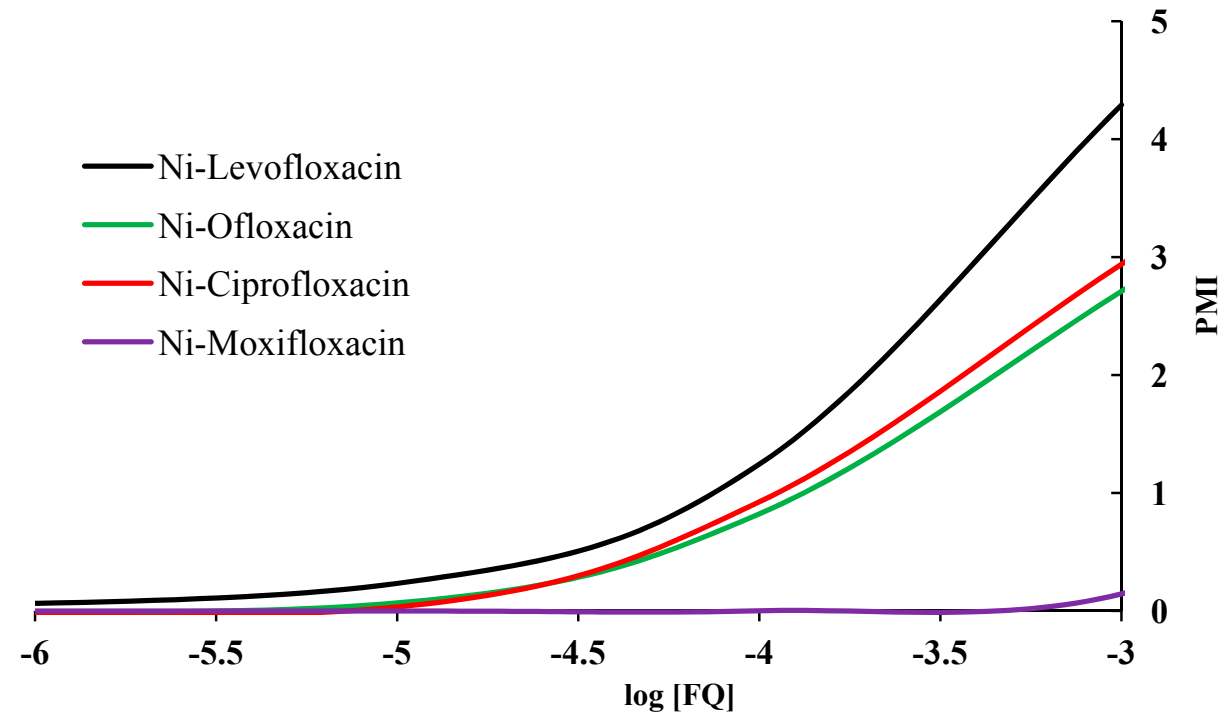

Table 11. Calculated bio-distribution of dominant $\mathrm{Zn}(\mathrm{II})$ species (\%) in human blood plasma in the precense of fluoroquinolones.

\begin{tabular}{|c|c|c|c|c|c|}
\hline \multirow{3}{*}{$\begin{array}{c}\text { Zn-LMW } \\
\text { species }\end{array}$} & \multicolumn{5}{|c|}{ Concentration of Fluoroquinolone $(\mathrm{mol} / \mathrm{L})$} \\
\hline & $\mathbf{0}$ & $1 \times 10^{-7}$ & $1 \times 10^{-5}$ & $1 \times 10^{-4}$ & $1 \times 10^{-3}$ \\
\hline & \multicolumn{5}{|c|}{ Moxifloxacin } \\
\hline ZnCysCit & 39.2 & 39.2 & 39.2 & 39.3 & 38.2 \\
\hline $\mathrm{ZnCys}_{2}$ & 19.4 & 19.4 & 19.4 & 19.3 & 18.3 \\
\hline ZnCysHis & 10.6 & 10.6 & 10.6 & 10.6 & 10.0 \\
\hline ZnHis & 3.6 & 3.6 & 3.6 & 3.6 & 3.4 \\
\hline \multirow[t]{2}{*}{$\mathrm{ZnHCys}_{2}$} & 2.7 & 2.7 & 2.7 & 2.7 & 2.6 \\
\hline & \multicolumn{5}{|c|}{ Levofloxacin } \\
\hline ZnCysCit & 39.2 & 39.2 & 39.3 & 39.8 & 28.2 \\
\hline $\mathrm{ZnCys}_{2}$ & 19.4 & 19.4 & 19.3 & 19.0 & 11.5 \\
\hline ZnCysHis & 10.6 & 10.6 & 10.6 & 10.4 & 6.0 \\
\hline ZnHis & 3.6 & 3.6 & 3.6 & 3.5 & 1.9 \\
\hline \multirow[t]{2}{*}{$\mathrm{ZnHCys}_{2}$} & 2.7 & 2.7 & 2.7 & 2.7 & 1.6 \\
\hline & \multicolumn{5}{|c|}{ Ciprofloxacin } \\
\hline ZnCysCit & 39.2 & 39.2 & 39.3 & 39.5 & 37.1 \\
\hline $\mathrm{ZnCys}_{2}$ & 19.4 & 19.4 & 19.4 & 19.2 & 16.1 \\
\hline ZnCysHis & 10.6 & 10.6 & 10.6 & 10.5 & 8.7 \\
\hline ZnHis & 3.6 & 3.6 & 3.6 & 3.6 & 2.9 \\
\hline \multirow[t]{2}{*}{$\mathrm{ZnHCys}_{2}$} & 2.7 & 2.7 & 2.7 & 2.7 & 2.3 \\
\hline & \multicolumn{5}{|c|}{ Ofloxacin } \\
\hline ZnCysCit & 39.2 & 39.2 & 38.8 & 35.6 & 19.7 \\
\hline $\mathrm{ZnCys}_{2}$ & 19.4 & 19.4 & 19.2 & 17.8 & 10.3 \\
\hline ZnCysHis & 10.6 & 10.6 & 10.5 & 9.6 & 5.2 \\
\hline ZnHis & 3.6 & 3.6 & 3.6 & 3.2 & 1.6 \\
\hline $\mathrm{ZnHCys}_{2}$ & 2.7 & 2.7 & 2.7 & 2.5 & 1.5 \\
\hline
\end{tabular}


PMI dependence on FQ's concentration is shown in Figure 15. The FQ's do not show much difference between themselves toward mobilizing power to $\mathrm{Zn}$.

Figure 15. The effect of fluoroquinolone ligands on plasma mobilization of zinc.

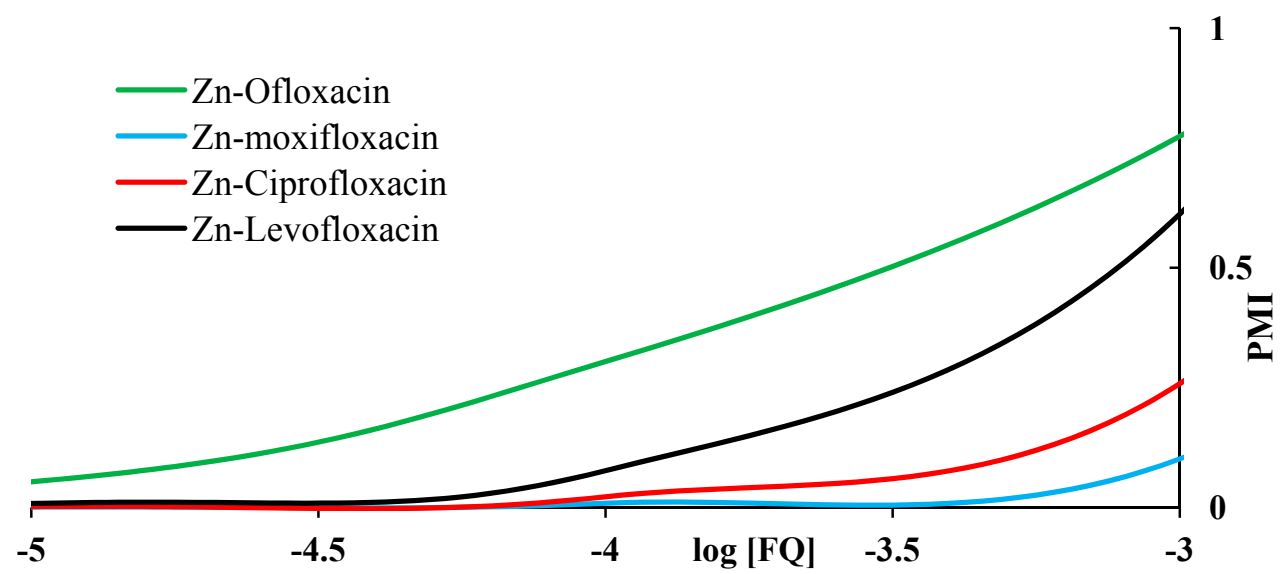

\section{Experimental Section}

\subsection{Reagents}

Moxifloxacin, (1-cyclopropyl-6-fluoro-8-methoxy-7-[(4a $S, 7 \mathrm{a} S)$-octahydropyrolo[3,4-b]pyridine-6yl]- 4-oxo-1,4-dihydroquinoline-3-carboxylic acid hydrochloride) and ciprofloxacin (1-cyclopropyl-6fluoro-4-oxo-7-(piperazin-1-yl)-quinoline-3-carboxylic acid) (declared purities $>99.9 \%$ ) were obtained from Bayer Pharma AG (Berlin, Germany); ofloxacin (9-fluoro-3-methyl-10-(4-methyl-1-piperazinyl)7-oxo-2,3-dihydro-7H-pyrido-(1,2,3-de)1,4-benzoxazine-6-carboxylic acid) and levofloxacin ((S)-9fluoro-2,3-dihydro-3-methyl-10-(4-methylpiperazin-1-yl)-7-oxo-7H-pyrido[1,2,3-de]-1,4-benzoxazine-6-carboxylic acid) ( $\geq 99.9 \%$ pure) were purchased from Sigma Aldrich (St. Louis, MO, USA). Nickel(II) chloride hexahydrate ( $\geq 98 \%$, Sigma Aldrich), copper(II) chloride dihydrate ( $\geq 99.9 \%$, Sigma Aldrich) and zinc(II) chloride hydrate ( $\geq 98 \%$, Sigma Aldrich) were utilized. Doubly distilled water was used for preparation of all solutions (conductivity less a $0.1 \mu \mathrm{S} \mathrm{cm} \mathrm{cm}^{-1}$ ). The solutions of fluoroquinolones $\left(5 \times 10^{-3} \mathrm{~mol} / \mathrm{L}\right)$ were prepared by direct weighing of standard substances.Metal salts were disolved in water with the addition of appropriate amount of $\mathrm{HCl}$ to avoid initial hydrolysis of metal ions. The concentration were determined by complexometric titration using EDTA and by electrogravimetry. The excess of $\mathrm{HCl}$ in the metal chloride stock solution was determined potentiometrically using Gran's method. A sodium hydroxide solution was prepared from concentrated volumetric solutions (p.a., Merck, NJ, USA), diluted with freshly boiled doubly distilled water followed by cooling under a constant flow of purified nitrogen. The alkali concentration was checked by titration against potassium hydrogen phthalate. Hydrochloric acid solution was made from $\mathrm{HCl}$ "Suprapure" (Merck) and standardized against tris(hydroxymethyl) aminomethane. A sodium chloride solution was prepared from $\mathrm{NaCl}$, (p.a., Merck), by dissolving the re-crystallized salt in twice-deionized water. The concentration of this solution was determined by evaporation of a known volume of solution to dryness at $573 \mathrm{~K}$ and weighing the residue. Nitrogen gas, used for stirring solutions and 
providing an inert atmosphere during the titrations, was purified by passing it through $10 \% \mathrm{NaOH}$ then $10 \% \mathrm{H}_{2} \mathrm{SO}_{4}$, alkaline solution of pyrogallol, $0.1 \mathrm{~mol} /$ Lsolution of $\mathrm{KCl}$ and finally distilled water.

\subsection{Instruments}

Potentiometric measurements were made on a Tacussel Isis $20000 \mathrm{pH}$ meter (Courthezon, Vaucluse, France, precision $\pm 0.1 \mathrm{mV}$ or $\pm 0.001 \mathrm{pH}$ units) equipped with a Radiometer combined electrode. A Metrohm Dosimat model 665 automatic burette with anti-diffusion tip (Herisau, Switzerland), was used for delivery of the titrant.

UV spectral measurements were performed on a double beam UV-Vis spectrophotometer model Lambda 35 (PerkinElmer, Waltham, MA, USA). Operational parameters were: scan speed, $2 \mathrm{~nm} / \mathrm{s}$, slit width, $0.3 \mathrm{~nm}$, photometric sensitivity, 0.2 abs. units. Matching pair of $1 \mathrm{~cm}$ quartz cuvettes was used for measuring the spectra.

Fluorescence spectra were collected on Shimadzu RF-1501 spectrofluorimeter (Kyoto, KYT, Japan) with a $150 \mathrm{~W}$ xenon lamp and $1.0 \times 1.0 \mathrm{~cm}$ quartz cells. The slit width was set to $10 \mathrm{~nm}$ on both the excitation and emission monochromators. To ensure reproducible experimental conditions instrument performance was checked daily using quinine sulphate solution $\left(4 \mathrm{~g} / \mathrm{L}\right.$ quinine in $\left.0.5 \mathrm{~mol} / \mathrm{LH}_{2} \mathrm{SO}_{4}\right)$.

ESI MS spectra were collected on an LCQ Fleet 3D Ion Trap Mass Spectrometer (Thermo Fisher Scientific, Waltham, MA, USA). ${ }^{1}$ H-NMR spectra were recorded on Varian Gemini 200 spectrometer (Palo Alto, CA, USA).

\subsection{Procedure}

\subsubsection{Potentiometric Titrations}

Potentiometric titrations were carried out in a double-walled glass vessel, thermostatted at $310 \mathrm{~K}$. The ionic strength of all test solutions was adjusted to $0.15 \mathrm{~mol} / \mathrm{Lwith}$ sodium chloride. All measurements were performed under a nitrogen atmosphere. The titration protocol was chosen in such a way that the protonation, hydrolysis and complexation reactions would proceed in the conditions as close to true equilibrium as possible. Usually stable potential readings were obtained in 3-5 min after addition of the titrant. If equilibrium could not be established within specified time interval the point was discarded. The electrode parameters, $E_{0}, Q$ and $E_{j}$ from Nernst equation: $E=E_{0}+Q \log h+E_{j}$ were determined by strong acid-strong base titration to check the system suitability. During the titrations of the test solutions the $E_{0}$ and $E_{j}$ were determined using the data in the acidic region where no hydrolysis or complexation takes place (assuming that $h$ is equal to the analytical concentration of proton), by plotting $E-Q \log h$ against $h$ and extrapolating the straight line so obtained to $h=0$. The free proton concentration was then calculated through the equation: $\log h=\left(E-E_{0}-E_{j}\right) / Q$ which was applied to the whole titration curve. All titrations were carried in duplicate. The agreement between duplicate titration was better than $1 \%$. The samples of FQ + metal ion solutions were titrated with sodium hydroxide and all titration were performed in the $\mathrm{pH}$ range from 2 to 11 with constant ionic strength $(\mathrm{I}=0.15 \mathrm{~mol} / \mathrm{LNaCl})$ and under purified nitrogen atmosphere at $310 \mathrm{~K}$. Molar ratios between metal ions and fluoroquinolones ranged from 1:1 to 1:2 for all M-FQ systems. 


\subsubsection{Spectrophotometric Measurements}

Spectra of solutions of FQ alone $\left(5 \times 10^{-5} \mathrm{~mol} / \mathrm{L}\right)$ and $\mathrm{FQ}+$ metal ion in the $\mathrm{pH}$ range $2.0-11.0$ in $0.15 \mathrm{~mol} / \mathrm{LNaCl}$ ionic medium, at $310 \mathrm{~K}$ were taken in the wavelength range $250-450 \mathrm{~nm}$. Metal concentration was held constant $\left(2.5 \times 10^{-5} \mathrm{~mol} / \mathrm{L}\right)$. The $\mathrm{pH}$ of all solution was adjusted by the addition of $0.1 \mathrm{~mol} / \mathrm{LHCl}$ or $0.1 \mathrm{~mol} / \mathrm{LNaOH}$. Solutions were left for $0.5 \mathrm{~h}$ before scanning. Another set of spectrophotometric data was performed as spectrophotometric titration. The solution from the titration cell was pumped after each addition of alkali to spectrophotometer flow through $10 \mathrm{~mm}$ quartz cuvette using peristaltic pump.

\subsubsection{Spectrofluorimetric Measurements}

The excitation and emission spectra were taken for either levofloxacin or ofloxacin $(2.0 \mathrm{mmol} / \mathrm{L})$ with and without presence of copper ion. Aliquots of $0.1 \mathrm{~mL}$ of standard solution of either levofloxacin or ofloxacin were transferred into $10 \mathrm{~mL}$ volumetric flask, using Ependorf pipette and in each flask $2 \mathrm{~mL}$ of phosphate buffer $(\mathrm{pH} 7.40)$ and different volumes $(0-0.3 \mathrm{~mL})$ of copper ion solution $(10 \mathrm{mmol} / \mathrm{L}))$ were added. After dilution to the mark with water and thorough mixing, the fluorescence intensity of each spectrum was measured in wavelength range 400-650 nm with excitation at $292 \mathrm{~nm}$.

\subsubsection{ESI-MS Measurements}

For ESI-MS measurements FQ-metal solutions were prepared in the FQ to metal ion concentration ratio $2: 1$ at the $\mathrm{pH} 4.5$ adjusted with ammonium formate buffer. Concentration of fluoroquinolone in solutions was $2 \times 10^{-4} \mathrm{~mol} / \mathrm{L}$. The ESI-source parameters were as follows: source voltage $4.7 \mathrm{kV}$, capillary voltage $23 \mathrm{~V}$, tube lens voltage $90 \mathrm{~V}$, capillary temperature $220{ }^{\circ} \mathrm{C}$, sheath gas flow $\left(\mathrm{N}_{2}\right) 32$ (arbitrary units). ESI-MS spectra were acquired by full range acquisition of $\mathrm{m} / z$ 200-2000. The normalized collision energy of the CID cell was set at 8-20 eV.

\subsubsection{NMR Measurements}

All ${ }^{1} \mathrm{H}-\mathrm{NMR}$ spectra were recorded in DMSO- $d_{6}$ and in $\mathrm{D}_{2} \mathrm{O}$ solutions. Typical conditions for ${ }^{1} \mathrm{H}-\mathrm{NMR}$ measurements were: spectral width $3,500 \mathrm{~Hz}$, pulse delay time $1 \mathrm{~s}$, no of scans 72 . Chemical shifts $(\delta, \mathrm{ppm})$ were obtained for 3-trimethylsilylpropionic acid- $\mathrm{d}_{4}$ sodium salt as an internal standard $(\delta=0.000 \mathrm{ppm})$.

\subsection{Data Treatment}

The species formed in the studied systems were characterized by the general equilibrium:

$$
p M^{2+}+q F Q^{-}+r H^{+} \leftrightarrow\left[M_{p} F Q_{q} H_{r}\right]^{(2 p+q-r)}
$$

and the corresponding constants are given by:

$$
\beta_{p, q, r}=\frac{\left[M_{p}\left(F Q_{q}\right) H_{r}\right]}{[M]^{p}[F Q]^{q}[H]^{r}}
$$


where $\mathrm{FQ}^{-}$is the deprotonated molecule of the ligand. Fully protonated fluoroquinolone is donated as $\mathrm{H}_{2} \mathrm{FQ}^{+}$. The concentration stability constants of complexes $\beta_{p, q, r}$ were calculated with the aid of the suite of computer programs Hyperquad2006 [17]. In Hyperquad calculations the identity and stability of complexes which give the best fit to the experimental data, were determinated by minimizing the error squares sum of the potentials, $U: U=\sum w_{i}\left(E_{o b s}-E_{c a l c}\right)^{2}$ where $w_{i}$ represents a statistical weight assigned to each point of titration curve, $E_{o b s}$ and $E_{c a l c}$ refer to the measured potential of the cell and the calculated one assuming the specific model and trial constants, respectively. Quality of fit was judged by usual statistical parameters: Pearsons test, $\chi^{2}$, standard deviation in potential residuals, $s$, and the difference between experimentally determined and calculated standard EMF of the cell. If this difference was higher than $1 \mathrm{mV}$ the titration was discarded. The spectrophotometric data were evaluated with Hyperquad2006 and pHab2006 programs. The composition, stability and molar absorptivities, $\varepsilon_{p, q, r}$ of complexes were determinated by minimizing the sum, $\mathrm{S}$, defined as: $\mathrm{S}=\sum\left(A_{o b s}-A_{\text {calc }}\right)^{2}$ where $A_{\text {obs }}$ and $A_{\text {calc }}$ refer to measured absorbance and that calculated according to equation: $A_{\text {calc }}=\sum \beta_{p, q, r}[M]^{p}[F Q]^{q}[H]^{r} \varepsilon_{p, q, r}$. Acceptance criteria for each particular model were: $\mathrm{S}$ lower than $1.0 \times 10^{-2}$ and standard deviation of the fit of the spectrum (SD) less than 0.08 units. For Hyperquad calculations the spectra were digitized at $2 \mathrm{~nm}$ intervals. The final model obtained in Hyperquad calculations was optimized.

\subsection{The Human Blood Plasma Model and Speciation Calculation}

In developing the computer model of blood plasma, we updated the May et al. model of blood plasma and constructed a model including nine metals, 43 ligands and over 6,100 complexes [5]. The free concentration of all metal ions (component) was calculated by solving a mass balance equation written for each component:

$$
C_{i}=\left[X_{i}\right]+\sum_{j=1}^{m} x_{j i} \beta_{j}\left(\prod_{k}\left[X_{k}\right]^{x_{j k}} \gamma_{k}^{x_{j k}}\right) \times \frac{1}{\gamma_{j}} i=1,2,3, \ldots, n
$$

where $C_{i}$ is the total analytical concentration of component $i,\left[X_{i}\right]$ the concentration of free component $i$, and $x_{j i}$ the stoichiometric factor of component $i$ in species $S_{j}$. The species $S_{j}$ is formed from the components $\mathrm{A}, \mathrm{B}, \mathrm{C} \ldots$ according to equations:

$$
\begin{gathered}
a A+b B+c C+\cdots=A_{a} B_{b} C_{c} \cdots \\
S_{j}=A_{a} B_{b} C_{c} \cdots \\
\beta_{j}=\frac{\left\{S_{j}\right\}}{\{A\}^{a}\{B\}^{b}\{C\}^{c} \cdots}
\end{gathered}
$$

where \{\} denotes activity, and a,b,c... are stoichiometric factors of components A, B, C in species $S_{j}$, respectively, and $\beta_{j}$ is the stability constant of $S_{j}$.

Total concentrations of all components were taken from published papers and Geigy tables [53-63]. The stability constants were extracted from the literature and were necessary adjusted to $310 \mathrm{~K}$ and ionic strength of $0.15 \mathrm{~mol} / \mathrm{L}$ [64-66]. The equilibrium constants not available in the literature were measured in this work or estimated using LFER approach. A complete list of complexes of components and constants was described in detail in our previous work [16]. 


\section{Conclusions}

Computer simulations are a useful way of predicting the effect of various exogenous ligands on the biodistribution of essential metal ions in biological fluids and tissues, particularly in human blood plasma. Fluoroquinolones affect to a significant degree the distribution of LMW species of the essential metal ions $\mathrm{Cu}$ and $\mathrm{Zn}$ and the non-essential one $\mathrm{Ni}$. The effect of fluoroquinolones originates from their pronounced tendency chelate aforementioned metal ions and compete with their major binders in human plasma-amino acids. The quantitative evaluation of the mobilizing effect demonstrates that fluoroquinolones are safe regarding their ability to disturb LMW complexation equilibria in blood plasma and consequently change the metabolism of $\mathrm{Cu}, \mathrm{Ni}$ and $\mathrm{Zn}$ ions. Thus, the amino-acid pool is metal protective in plasma and as computer simulation results show, quinolones cannot significantly disturb these equilibria under normal concentration conditions. However, if such conditions are (temporarily) changed, for example, after intravenous infusion of the drug the metal-quinolone interactions may become noticeable and consequently metal mobilization may take place. The observed effect emphasizes the need to take into the consideration not only free quinolones, but also metallo-quinolone complexes in any explanation of their antibacterial action.

\section{Acknowledgments}

Financial support from the Ministry of Science and Technological Development of Serbia, under the project 172016 , is gratefully acknowledged.

\section{Author Contributions}

PDj designed the research and wrote the paper, IJ, LjJ and NI performed the experiments and computer calculations, MJS analyzed the data. All authors read and approved the final manuscript.

\section{Conflicts of Interest}

The authors declare no conflict of interest.

\section{References}

1. Reilly, C. The Nutritional Trace Metals; Blackwell: Oxford, UK, 2004.

2. Brätter, P.; Raab, A.; Richarz, A. Trace element speciation in human body fluids; In Trace Elements in Man and Animals 10; Roussel, A.M., Anderson, R.A., Favrier, A.E., Eds; Kluwer Academic/Plenum Publishers; New York, NY, USA, 2000, 145-153.

3. Milačić, R. Species in the environment, food, medicine and occupational health. In Handbook of Elemental Speciation II; Rita, C., Joe, C., Helen, C., Klaus, H., Eds.; John Wiley and Sons: New York, NY, USA, 2005.

4. Sanz-Medel, A.; Cabezuelo, A.B.C.; Milačić, R.; Polak, T.B. The chemical speciation of aluminium in human serum. Coord. Chem. Rev. 2002, 228, 373-383. 
5. May, P.M.; Linder, P.W. Computer simulation of metal-ion equilibria in biofluids: Models for the low-molecular weight complex distribution of Clacium(II), magnesium(II), Manganese(II), Iron(III), Copper(II), Zinc(II) and Lead(II) ions in human blood plasma. J. Chem. Soc. Dalton. Trans. 1977, 6, 588-595.

6. May, P.M; Linder, P.W. Ambivalent effect of protein binding on computed distributions of metal ions complexed by ligands in blood plasma. Experientia 1976, 32, 1492-1494.

7. Forbes, J.R.; Gros, P. Divalent-metal ion transport by NRAMP proteins at the interface of host-pathogen interactios. TRENDS Microbiol. 2001, 9, 397-403.

8. Linder, M.C.; Hazegh-Azam, M. Copper biochemistry and molecular biology. Am. J. Clin. Nutr. 1996, 63, 797S-811S.

9. Ho, D.H.; Lin, J.R.; Brown, N.S.; Newman, R.A. Bioavailability of gallium nitrate. Eur. J. Pharmacol. 1990, 183, 1200-1201.

10. Jenkins, D.W. Nickel accumulation in terrestrial wildlife. In Nickel in the Environment; Nriagu, J.O., Ed.; John Wiley and Sons: New York, NY, USA, 1980; pp. 457-462.

11. Harris, W.; Keen, C. Calculation of the distribution of zinc in a computer model of human serum. J. Nutr. 1989, 119, 1677-1682.

12. Turel, I. The interactions of metal ions with quinolone antibacterial agents. Coord. Chem. Rev. 2002, 232, 27-47.

13. Uivarosi, V. Metal complex of quinolone antibiotics and their applications: An update. Molecules 2013, 18, 11153-11197.

14. Sarafin, A.; Stanczak, A. The complexes of metal ions with fluoroquinolones. Russ. J. Coord. Chem. 2009, 35, 81-95.

15. May, P.M; Linder, P.W. Computer simulation of chelation therapy. FEBS Lett. 1977, 78, 134-138.

16. Jakovljević, I.; Petrović, Đ.; Joksović, L.; Lazarević, I.; Đurđević, P. Computer simulation of speciation of trivalent aluminum, gadolinium and yttrium ions in human blood plasma. Acta Chim. Slov. 2013, 60, 861-869.

17. Gans, P.; Sabatini, A.; Vacca, A. Investigation of equilibria in solution. Determination of equilibrium constants with the HYPERQUAD suite of programs. Talanta 1996, 43, 1739-1753.

18. Feio, M.J.; Sousa, I.; Ferreira, M.; Cunha-Silva, L.; Saraiva, R.G.; Queiros, C.; Alexandre, J.G.; Claro, V.; Mendes, A.; Ortiz, R.; et al. Fluoroquinolone-metal complexes: A route to counteract bacterial resistance? J. Inorg. Biochem. 2014, 138, 129-143.

19. Drakopoulos, A.I.; Ioannou, P.C. Spectrofluorimetric study of the acid-base equlibria and complexation bevavior of the fluoroquinoloe antibiotics ofloxacin, norfloxacin, ciprofloxacin and pefloxacin in aqueous solution. Anal. Chim. Acta 1997, 354, 197-204.

20. Sun, J.; Sakai, S.; Tauchi, Y.; Deguchi, Y.; Chen, J.; Zhang, R.; Morimoto, K. Determination of lipophilicity of two quinolone antibacterials, ciprofloxacin and grepafloxacin, in the protonation equilibrium. Eur. J. Pharm. Biopharm. 2002, 54, 51-58.

21. Lozano, E.J.; Marqués, I.; Barrón, D.; Beltrán, J.L.; Barbosa, J. Determination of pKa values of quinolones from mobility and spectroscopic data obtained by capillary electrophoresis and a diode array detector. Anal. Chim. Acta 2002, 464, 37-45. 
22. Lee, D.S.; Han, H.J.; Kim, K.; Park, W.B.; Cho, J.K.; Kim, J.H. Dissociation and complexation of fluoroquinolone analogue. J. Pharm. Biomed. Anal. 1994, 12, 157-164.

23. Barbosa, J.; Bergés, R.; Toro, I.; Nebot, V.S. Protonation equilibria of quinolone antibacterials in acetonitrile-water mobile phase used in LC. Talanta 1997, 44, 1271-1283.

24. Park, H.R.; Chung, K.Y.; Lee, H.C.; Lee, J.K.; Bark, K.M. Ionization and divalent cation complexation of quinolone antibiotics in aqueous solution. Bull. Korean Chem. Soc. 2000, 21, 849-854.

25. Langlois, M.H.; Montagut, M.; Dubost, J.P.; Grellet, J.; Saux, M.C. Protonation equilibrium and lipophilicity of moxifloxacin. J. Pharm. Biomed. Anal. 2005, 37, 389-393.

26. Laban-Djurdjevic, A.; Jelikic-Stankov, M.; Djurdjevic, P. Optimization and validation of the direct HPLC method for the determination of moxifloxacin in plasma. J. Chromatogr. B 2006, 844, 104-111.

27. Neves, P.; Leite, A.; Rangel, M.; de Castro, B.; Paula, G. Influence of structural factors on the enhanced activity of moxifloxacin: A fluorescence and EPR spectroscopic study. Anal. Bioanal. Chem. 2007, 387, 1543-1552.

28. Djurdjevic, P.; Joksovic, L.J.; Jelic, R.; Djurdjevic, A.; Jelikic-Stankov, M. Solution equilibria between aluminum(III) ion and some fluoroquinolone family members. Spectroscopic and potentiometric study. Chem. Pharm. Bull. 2007, 55, 1689-1699.

29. Djurdjevic, P.; Ratomir, J.; Joksovic, L.J.; Lazarevic, I.; Jelikic-Stankov, M. Study of solution equilibria between Gadolinium(III) ion and Moxifloxacin. Acta Chim. Slov. 2010, 57, 386-397.

30. Sousa, I.; Claro, V.; Lino, J.P.; Amaral, A.L.; Cunha-Silva, L.; Castro, B.M.; Feio, J.; Pereira, E.; Gameiro, P. Synthesis, characterization and antibacterial studies of a copper(II) levofloxacin ternary complex. J. Inorg. Biochem. 2012, 110, 64-71.

31. Gameiro, P.; Rodrigues, C.; Baptista, T.; Sousa, I.; Castro, B. Solution studies on binary and ternary complexes od copper(II) with some fluoroquinolones and 1, 10-phenanthroline: Antimicrobial activity of ternary metalloantibiotics. Int. J. Pharm. 2007, 334, 129-136.

32. Urbaniak, B.; Kokot, Z.J. Analysis of the factors that significantly influence the stability of the fluoroquinolone-metal complexes. Ana. Chim. Acta 2009, 647, 54-59.

33. Wallis, S.C.; Gahan, L.R.; Charles, B.G.; Hambley, T.W.; Duckworth, P.A. Copper(II) complexes of the fluoroquinolone antimicrobial ciprofloxacin. Synthesis, X-Ray structural characterization and potentiometric study. J. Inorg. Biochem. 1996, 62, 1-16.

34. Turel, I.; Bukovec, N. Complex formation between some metals and a quinolone family member (Ciprofloxacin). Polyhedron 1996, 15, 269-275.

35. Macías, B.; Villa, M.V.; Rubio, I.; Castiñeiras, A.; Borrás, J. Complexes of Ni(II) and Cu(II) with ofloxacin. Crystal structure of a new $\mathrm{Cu}(\mathrm{II})$ ofloxacin complex. J. Inorg. Biochem. 2001, 8, $163-170$.

36. Hernandez, G.J.; Perello, L.; Ortiz, R.; Alzuet, G.; Gonzalez-Alvarez, M.; Liu-Gonzalez, M. Synthesis, structure and biological properties of several binary and ternary complexes of copper(II) with ciprofloxacin and 1,10 phenanthroline. Polyhedron 2009, 28, 138-144.

37. Anacona, J.R.; Toledo, C. Synthesis and antibacterial activity of metal complexes of ciprofloxacin. Trans. Met. Chem. 2001, 26, 228-231. 
38. Sultana, N.; Arayne, M.S.; Rizvi, S.B.S.; Haroon, U.; Mesaik, M.A. Synthesis, spectroscopic, and biological evaluation of some levofloxacin metal complexes. Med. Chem. Res. 2013, 22, 1371-1377.

39. Živec, P.; Perdih, F.; Turel, I.; Giester, G.; Psomas, G. Different types of copper complexes with the quinolone antimicrobial drugs ofloxacin and norfloxacin: Structure, DNA- and albumin-binding. J. Inorg. Biochem. 2012, 117, 35-47.

40. Sagdinc, S.; Bayar, S. Spectroscopic studies on the interaction of ofloxacin with metals. J. Mol. Struct. 2004, 691, 107-113.

41. Ge, R.-G.; Wang, D.-X.; Hao, M.-C.; Sun, X.-S. Nickel trafficking system responsible for urease maturatuin in Helicobacter pyroli. World J. Gastroenterol. 2013, 19, 8211-8218.

42. Nista, E.C.; Candelli, M.; Zocco, M.A.; Cazzato, I.A.; Cremonini, F.; Ojetti, V.; Santoro, M.; Finizio, R.; Pignataro, G.; Cammarota, G.; et al. Moxifloxacin-based strategies for first-line treatment of Helicobaceter pylori infection. Aliment. Pharmacol. Ther. 2005, 21, 1241-1247.

43. Stern, O.; Volmer, M. Über die abklingzeit der fluoreszenz. Physik Zeitschr. 1919, 20, 183-188.

44. Xia, Q.; Yang, Y.; Liu, M. Spectrofluorimetric determination of fluoroquinolones in honey with 2,3-dichloro-5,6-dicyano-1,4-benzoquinone in the presence of $\beta$-cyclodextrin. J. Fluoresc. 2013, 23, 713-723.

45. Pan, B.; Han, X.; Wu, M.; Peng, H.; Zhang, D.; Li, H.; Xing, B. Temperature dependence of ofloxacin fluorescence quenching and complexation by $\mathrm{Cu}(\mathrm{II})$. Environ. Pollut. 2012, 171, 168-173.

46. Parker, C.A.; Rees, W.T. Fluorescence Spectrometry. Analyst 1962, 87, 83-111.

47. Parker, C.A.; Barnes, W.J. Some experiments with spectrofluorimeters and filter fluorimeters, Analyst 1957, 82, 606-618.

48. Gu, Q.; Kenny, J.E. Improvement of inner filter effect correction based on determination of effective geometric parameters using a convential fluorimeter. Anal. Chem. 2009, 81, 420-426.

49. Wagenlehnera, F.M.E.; Keesb, F.; Weidnera, W.; Wagenlehnerc, C.; Naberd, K.G. Concentrations of moxifloxacin in plasma and urine, and penetration into prostatic fluid and ejaculate, following single oral administration of $400 \mathrm{mg}$ to healthy volunteers. Int. J. Antimicrob. Agents 2008, 31, 21-26.

50. Psomas, G.; Kessissoglou, D.P. Quinolones and non-steroidal anti-inflammatory drugs interacting with copper(II), nickel(II), cobalt(II) and zinc(II): Structural features, biological evaluation and perspectives. Dalton Trans. 2013, 42, 6252-6276.

51. Cole, A.; Furnival, C.; Huang, Z.X.; Jones, D.C.; May, P.M.; Smith, G.L.; Whittake, J.; Williams, D.R. Computer simulation models foe the low-molecular-weight complex distribution of Cadmium(II) and Nickel(II) in human blood plasma. Inorg. Chim. Acta 1985, 108, 165-171.

52. Stojanović, D.; Nikić, D.; Lazarević, K. The level of nickel in smoker's blood and urine. Cent. Eur. J. Public Health 2004, 12, 187-189.

53. Dayde, S.; Filella, M.; Berthon, G. Aluminum speciation studies in biological fluids. Part 3. Quantitative investigation of aluminum-phosphate complexes and assessment of their potential significance in vivo. J. Inorg. Biochem. 1990, 38, 241-259.

54. Jackson, G.E. Aluminium, gallium and indium in biological fluids-a computer model of blood plasma. Polyhedron 1990, 9, 163-170. 
55. Kiss, T.; Lakatos, A.; Kiss, E.; Martin, R.B. In Interaction of Al(III) with Biomolecules: Bioinorganic Chemistry and Biological Implication in Cytotoxic, Mutagenic and Carcinogenic Potential of Heavy Metals Related to Human Environment; Hadjiliadis, N., Ed.; Kluwer: Dordrecht, The Netherlands, 1997; Volume 26, pp. 241-251.

56. Lakatos, A.; Evanics, F.; Dombi, G.; Bartani, R.; Kiss, T. Speciation of $\mathrm{Al}^{\mathrm{III}}$ in blood serum-the Al(III)-citrate-phosphate ternary system. Eur. J. Inorg. Chem. 2001, 12, 3079-3086.

57. Duffield, J.R.; Edwards, K.; Evans, D.A.; Morrish, D.M.; Vobe, R.A.; Williams, D.R. Low molecular mass aluminum complex speciation in biofluids. J. Coord. Chem. 1991, 23, 277-290.

58. Harris, W.R. Equilibrium model for speciation of aluminum in serum. Clin. Chem. 1992, 38, 1809-1818.

59. Clevette, D.J.; Orvig, C. Comparison of ligands of differing denticity and basicity for the in vivo chelation of aluminium and gallium. Polyhedron 1990, 9, 151-161.

60. Harris, W.R.; Wang, Z.; Hamada, Y.Z. Competition between transferrin and the serum ligands citrate and phosphate for the binding of aluminum. Inorg. Chem. 2003, 42, 3262-3273.

61. Jackson, G.E.; Wynchank, S.; Woudenberg, M. Gadolinium (III) complex equilibria: The implications for Gd(III) MRI contrast agents. Magn. Reson. Med. 1990, 16, 57-66.

62. Silwood, C.J.L.; Grootveld, M. Evaluation of the speciation status of aluminium(III) ions in isolated osteoarthritic knee-joint synovial fluid. Biochim. Biophys. Acta 2005, 1725, 327-339.

63. Diem, K., Lentner, C., Eds. Documenta Geigy Scientific Tables, 7th ed.; CIBA-Geigy Limited: Basel, Switzerland, 1970.

64. Smith, R.M.; Martell, A.E.; Motekaitis, R.J. NIST Standard Reference Database 46, NIST Critically Selected Stability Constants of Metal Complexes Database, Version 8.0; National Institute of Standards and Technology: Gaithersburg, MD, USA, 2004.

65. Pettit, L.D.; Powell, K.J. The IUPAC Stability Constants Database, SC-Database for Windows, Academic Software; IUPAC: Otley, UK, 2012.

66. May, P.M.; Murray, K. Jess, a joint expert speciation system-II. The thermodynamic database. Talanta 1991, 38, 1409-1417.

Sample Availability: Samples of the compounds are not available from the authors.

(C) 2014 by the authors; licensee MDPI, Basel, Switzerland. This article is an open access article distributed under the terms and conditions of the Creative Commons Attribution license (http://creativecommons.org/licenses/by/3.0/). 